UNIVERSIDADE DE SÃO PAULO

FACULDADE DE ODONTOLOGIA

\title{
ESTUDO DAS CONDIÇÕES DE SAÚDE BUCAL \\ E NECESSIDADES DE TRATAMENTO EM \\ PACIENTES DO CURSO DE ODONTOLOGIA \\ DA UNIVERSIDADE FEDERAL DO PARÁ
}

MARIZELI VIANA DE ARAGÃo ARAÚJO

Dissertação apresentada à Faculdade de Odontologia da Universidade de São Paulo, para obter o Título de Mestre, pelo Programa de Pós-Graduação em Odontologia. Mestrado Interinstitucional USP - UFPA.

Área de Concentração: Clínica Integrada.

São Paulo

2003 
Data da Defesa:

Comissão Julgadora

$\operatorname{Prof}(a) . \operatorname{Dr}(a)$

Julgamento:

Assinatura:

$\operatorname{Prof}(a) . \operatorname{Dr}(a)$

Julgamento:

Assinatura:

$\operatorname{Prof}(\mathrm{a}) . \operatorname{Dr}(\mathrm{a})$

Julgamento:

Assinatura: 


\title{
ESTUDO DAS CONDIÇÕES DE SAÚDE BUCAL \\ E NECESSIDADES DE TRATAMENTO EM \\ PACIENTES DO CURSO DE ODONTOLOGIA \\ DA UNIVERSIDADE FEDERAL DO PARÁ
}

\author{
MARIZELI VIANA DE ARAGÃo ARAÚJO \\ Dissertação apresentada à Faculdade de \\ Odontologia da Universidade de São Paulo, \\ para obter o Título de Mestre, pelo Programa \\ de Pós-Graduação em Odontologia. Mestrado \\ Interinstitucional USP - UFPA. \\ Área de Concentração: Clínica Integrada. \\ Orientador: Prof. Dr. Nicolau Tortamano \\ Co-Orientadora: \\ Profa. Dra. Regina Fátima Feio Barroso
}

São Paulo

2003 


\section{DEDICATÓRIA}

$\mathcal{A}$ Deus por toda a proteção ao longo de minfia vida.

Aos meus pais, Zilomar e Maria gosé, meus mestres na arte da vida, que me ensinaram a viver com honestidade, lealdade e amor a Deus e ao próximo, sempre apoiando e incentivando-me em todos os momentos de minfa vida.

Ao meu marido Izamir, companheiro de vida e de mestrado, fonte constante de apoio e incentivo, grande responsável pela minha iniciação na docência universitária, transmitindo seus ensinamentos e experiências, com amor, carinko, compreensãa.

Ao meu irmão Ismael, pelo apoio, carinto e amizade constante em nossas vidas. 


\section{AGRADECIMENTOS}

A Comissão de Pós-Graduação da Universidade de São Paulo e a Universidade Federal do Pará que na pessoa do Prof. Dr. Cristovam Diniz, ex- reitor desta Instituição e do Magnífico Reitor Prof. Dr. Alex Bolonha Fiúza de Melo, tornaram possível a realização deste Mestrado.

Aos Professores da Disciplina de Clínica Integrada da Universidade de São Paulo, particularmente aos Professores Doutores Nicolau Tortamano e Rodney Garcia Rocha, que não se furtaram a mais uma batalha para a realização de um novo Mestrado Interinstitucional.

Ao Prof. Dr. Flávio Eduardo Guillin Perez, pela constante disponibilidade, atenção, apoio e sugestões recebidas durante todo o Curso de Mestrado e realização desta dissertação.

À companheira Regina, minha co-orientadora, que acompanhou de perto a realização deste trabalho em todas as fases, meu especial muito obrigada. 
Aos colegas de Mestrado: Izamir, Wagner, Maneschy, Paulo, David Normando, Davi Lavareda, Lurdete, Simone, Jesuína, Ceci, Vaneska, Renata, Luciana e Andréa, que dividiram todas as angústias, momentos difíceis e também alegres no decorrer do curso, formando uma nova família.

À Vilma, nova amiga conhecida nesta jornada, pelo seu carinho e apoio durante o realização do Mestrado.

Ao Serviço Social do Curso de Odontologia da Universidade Federal do Pará, que colaborou na obtenção da amostra para este trabalho.

Aos funcionários da Biblioteca da Faculdade de Odontologia da Universidade de São Paulo, em especial Luzia Marilda Moraes, Maria Aparecida e S. Antônio, pela atenção e carinho recebidos durante a realização do Mestrado e auxílio na confecção deste trabalho.

Aos meus alunos de Saúde Coletiva do ano de 2000/1, Débora Gomes Cardoso e Hélder Henrique da Costa Pinheiro, monitores da disciplina, que colaboraram como anotadores neste trabalho.

À Sandra Lima de Souza, responsável pela parte estatística deste trabalho.

Aos pacientes que concordaram em participar desta pesquisa, tornando possível sua realização. 


\section{SUMÁRIO}

p.

LISTA DE FIGURAS E GRÁFICOS

LISTA DE TABELAS E QUADROS

LISTA DE ABREVIATURAS E SIGLAS

RESUMO

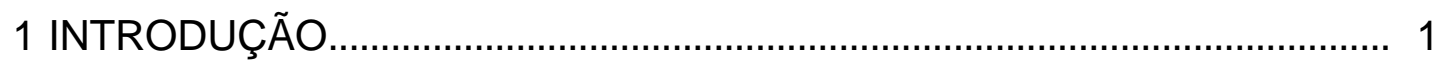

2 REVISÃO DA LITERATURA ................................................................. 4

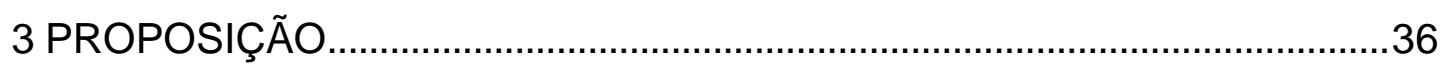

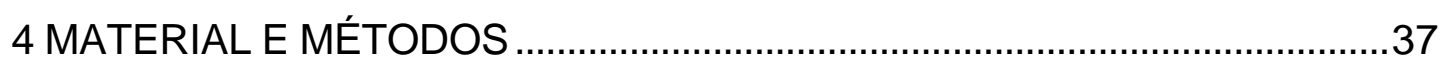

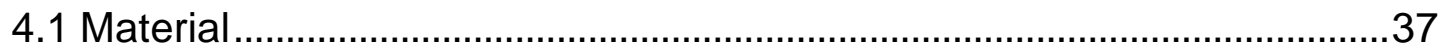

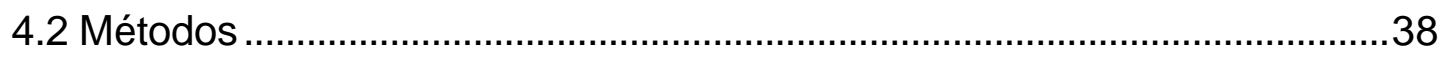

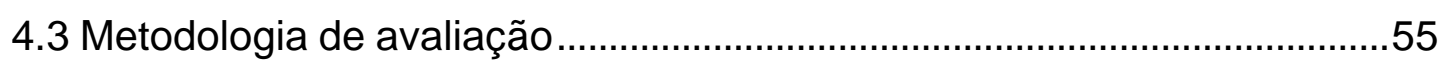

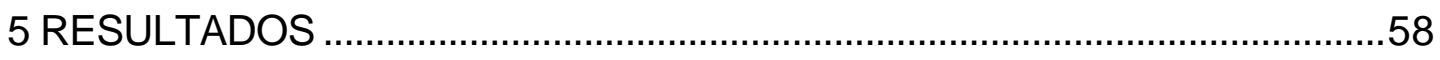

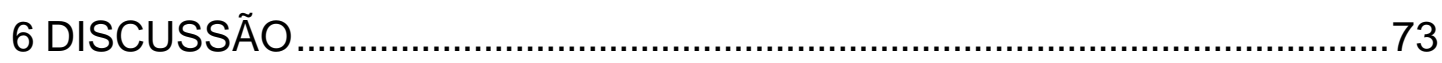

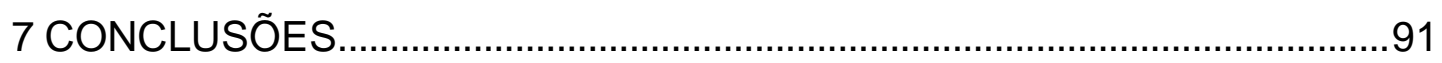

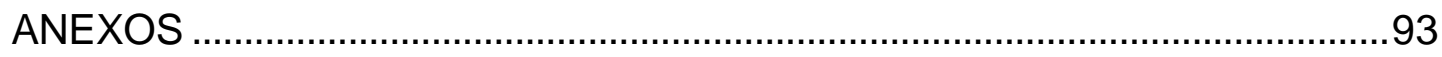

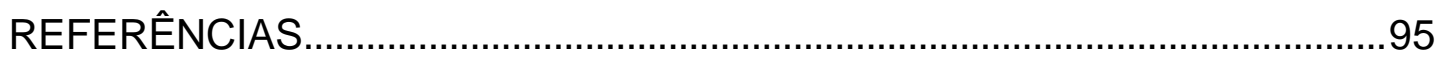

SUMMARY

APÊNDICES 


\section{LISTA DE FIGURAS E GRÁFICOS}

Figura 4.1 - Sonda CPI, ilustrando as marcações com as distâncias, em milímetros, àponta da sonda. .40

Figura 4.2 - Códigos para uso de prótese. .41

Figura 4.3 - Códigos para necessidade de prótese .42

Figura 4.4 - Divisão da arcada em sextantes e destaque dos dentes-índices para $\mathrm{CPI}$ .51

Figura 4.5 - Codificação do Índice Periodontal Comunitário (CPI), ilustrando a posição da sonda para o exame .53

Gráfico 5.1 - Distribuição segundo o tempo decorrido desde o último tratamento odontológico em 120 pacientes examinados no Curso de Odontologia da UFPA, 2002. .59 
Gráfico 5.2 - Índice Cariados, Perdidos e Obturados (ICPO-D) por sexo e faixas etárias, em 120 pacientes examinados no Curso de

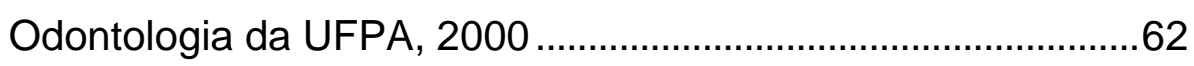

Gráfico 5.3 - Relação entre o ICPO-D e necessidade de prótese em 120 pacientes examinados no Curso de Odontologia da UFPA......72 


\section{LISTA DE TABELAS E QUADROS}

Tabela 2.1 - Classificação do ataque de cárie com base nos valores de CPO aos 12 anos de idade 12

Tabela 2.2 - Metas da OMS para os anos 2000 e 2010 .13

Tabela 5.1 - Distribuição em percentual e números absolutos, segundo faixas etárias e sexo de 120 pacientes examinados no Curso de Odontologia da UFPA, 2002 .58

Tabela 5.2 - Distribuição em percentual e números absolutos, segundo o gênero e etnia dos 120 pacientes examinados no Curso de Odontologia da UFPA, 2002 .59

Tabela 5.3 - ICDNT das coroas dentárias permanentes por faixa etária, em média e percentual, nos 120 pacientes examinados no Curso de Odontologia da UFPA, 2002. 60 
Tabela 5.4 - ICDNT das coroas dentárias temporárias por faixa etária, em 120 pacientes examinados no Curso de Odontologia da UFPA, 2002

Tabela 5.5 - ICDNT das raízes dentárias por faixa etária, em 120 pacientes examinados no Curso de Odontologia da UFPA, 2002

Tabela 5.6 - Índice Cariados, Perdidos e Obturados (CPO-D) por sexo e faixas etárias, em 120 pacientes examinados no Curso de Odontologia da UFPA, 2000 62

Tabela 5.7 - Índice cariados, perdidos e obturados (Iceo-d) para as faixas etárias, em 120 pacientes examinados no Curso de Odontologia da UFPA, 2000 .63

Tabela 5.8 - Distribuição dos dentes expressos em percentual e média por indivíduo, classificados segundo a necessidade de tratamento, através do ICDNT por faixa etária, em 120 pacientes examinados no Curso de Odontologia da UFPA, 2002 64

Tabela 5.9 - Distribuição das condições de saúde periodontal por sextante, em percentual e média, segundo o CPITN, em 120 pacientes examinados no Curso de Odontologia da UFPA, 2002 .65 
Tabela 5.10 - Distribuição do número de indivíduos, segundo a pior condição periodontal encontrada, em 120 pacientes examinados no Curso de Odontologia da UFPA, 2002. .66

Tabela 5.11 - Distribuição das necessidades de tratamento periodontal por sextante, em percentual e média, segundo o CPITN em 120 pacientes examinados no Curso de Odontologia da UFPA, 2002

Tabela 5.12 - Distribuição do uso de prótese superior por sexo, nas diversas faixas etárias, em 120 pacientes examinados no Curso de Odontologia da UFPA, 2002 .68

Tabela 5.13 - Distribuição do uso de prótese inferior por sexo, nas diversas faixas etárias, em 120 pacientes examinados no Curso de Odontologia da UFPA, 2002 .68

Tabela 5.14 - Distribuição em número absoluto e percentual da necessidade de prótese superior nas diversas faixas etárias, em 120 pacientes examinados no Curso de Odontologia da UFPA, 2002 .69

Tabela 5.15 - Distribuição em número absoluto e percentual da necessidade de prótese inferior nas diversas faixas etárias, em 120 pacientes examinados no Curso de Odontologia da UFPA, 2002 69 
Tabela 5.16 - Distribuição da necessidade de prótese superior por sexo, nas diversas faixas etárias, em 120 pacientes examinados no Curso de Odontologia da UFPA, 2002 .......................................70

Tabela 5.17 - Distribuição da necessidade de prótese inferior por sexo, nas diversas faixas etárias, em 120 pacientes examinados no Curso de Odontologia da UFPA, 2002 .70

Tabela 5.18 - Relação entre o ICPO-D e necessidade de prótese em 120 pacientes examinados no Curso de Odontologia da UFPA......71

Tabela 6.1 - Metas em Saúde Bucal relativas à prevalência da cárie dentária, nos anos 2000 e 2010 e resultados obtidos no levantamento das "Condições de Saúde Bucal do Curso de Odontologia da UFPA em 2002" .78

Quadro 4.1 - Códigos para condição de cárie dentária .48

Quadro 4.2 - Códigos para necessidade de tratamento de cárie dentária ....50

Quadro 4.3 - Códigos para condição periodontal. .54

Quadro 4.4 - Códigos para necessidade de tratamento periodontal .54 


\section{LISTA DE ABREVIATURAS E SIGLAS}

\begin{tabular}{ll} 
USP & Universidade de São Paulo \\
UFPA & Universidade Federal do Pará \\
SB 2000 & Projeto de Condições de Saúde Bucal Brasileira no Ano 2000 \\
OMS & Organização Mundial de Saúde \\
FDI & Federação Dentária Internacional \\
SESI & Serviço Social da Indústria \\
CPO & Cariados, perdidos e obturados \\
ICPO-D & Índice dos dentes permanentes cariados, perdidos e obturados \\
ICPO-S & Índice das superfícies dentárias cariadas, perdidas e obturadas \\
ICDNT & Índice de condição dentária e necessidade de tratamento \\
CPITN & Índice periodontal comunitário de necessidades de tratamento \\
CPI & Índice periodontal comunitário \\
& média \\
\hline
\end{tabular}




\section{RESUMO}

\section{ESTUDO DAS CONDIÇÕES DE SAÚDE BUCAL E NECESSIDADES \\ DE TRATAMENTO EM PACIENTES DO CURSO DE ODONTOLOGIA DA UNIVERSIDADE FEDERAL DO PARÁ}

Brasil tem sido freqüentemente referido como um país detentor de altos índices de prevalência de doenças bucais, em particular a cárie dentária e a doença periodontal. O presente trabalho, teve como principais objetivos avaliar as condições de saúde bucal e necessidades de tratamento em cárie dentária, doença periodontal e prótese, dos pacientes que procuram atendimento no Curso de Odontologia da Universidade Federal do Pará, para verificar a prevalência destas doenças. Foram examinados 120 pacientes, divididos em quatro grupos: 12 , 15 a 19, 35 a 44 e 65 a 74 anos, durante o ano de 2002. Os parâmetros utilizados foram o ICDNT, CPITN e uso e necessidade de prótese dentária, recomendados pela OMS. Os pacientes que procuraram atendimento no Curso de Odontologia da Universidade Federal do Pará, foram em maior prevalência, de cor parda e do sexo feminino. O Índice CPO-D geral da amostra foi de 11,91 e de 1,63 para os 12 anos, 4,63 para a faixa etária de 15 a 19 anos, 16,40 dos 35 aos 44 anos e 25,01 para a faixa etária de 65 a 74 anos. A necessidade de 
tratamento da cárie dentária predominante foi o tratamento restaurador de uma, duas ou mais faces. Em relação a pior condição periodontal encontrada nos pacientes, foi detectada uma alta prevalência da doença periodontal, com alto percentual de sextantes excluídos, seguido da presença de cálculo e bolsa de 4 a $5 \mathrm{~mm}$, levando a uma necessidade de tratamento periodontal concentrada em raspagem, profilaxia e educação de higiene oral. $\mathrm{O}$ uso de prótese ficou concentrado nas faixas etárias de 35 a 44 anos e 65 a 74 anos. Em relação a necessidade de prótese foi observado que $45 \%$ dos pacientes necessitavam de prótese superior e $54,2 \%$ de prótese inferior. Quando analisada a necessidade de prótese em relação ao sexo, $41,81 \%$ dos pacientes do sexo masculino e 67,69 do sexo feminino, necessitavam de prótese, demonstrando uma maior necessidade nas mulheres examinadas. 


\section{INTRODUÇÃO}

Os levantamentos epidemiológicos em saúde bucal proporcionam uma base sólida para as estimativas das condições de saúde e necessidades de tratamento de uma população. Eles funcionam como um banco de dados confiável para o desenvolvimento de programas de saúde destinados à resolução das doenças bucais mais prevalentes na população estudada.

No Brasil, os principais problemas bucais são a cárie dentária e a doença periodontal. $15 \%$ da população do país é desdentada. A maior parte da população brasileira não têm acesso à informação e a programas educacionais, muito menos a um tratamento odontológico. Para mudar esta realidade é necessário conhecer as condições de saúde e necessidades de tratamento.

As Universidades, como eixo central da academia, têm responsabilidade de executar e promover a realização de levantamentos epidemiológicos que possam subsidiar políticas públicas, capazes de reverter a condição de saúde da população.

O Curso de Odontologia da Universidade Federal do Pará está implantando um novo projeto pedagógico, visando corrigir problemas 
detectados no antigo currículo através de duas Avaliações das Condições de Ofertas de Ensino de Graduação efetuadas pela Comissão de Especialistas de Ensino do Ministério da Educação, nos anos de 1998 e 2000.

O Novo Projeto Pedagógico está atualmente no sétimo período, de um total de dez períodos. A concepção filosófico-pedagógica está baseada em uma filosofia preventiva em todos os níveis de atenção, levando o discente a compreender o binômio saúde-doença como processo social, onde as ações curativas não são a única meta a alcançar.

Com essa concepção, busca-se o conhecimento da realidade econômica social e das condições bucais encontradas na população habitante da região onde o novo profissional deverá atuar. A interdisciplinalidade é o ponto forte ao longo de toda a rede de atividades curriculares com o objetivo principal de graduar o cirurgião-dentista com sólida formação técnica, científica, humanística e ética, orientado para a promoção de saúde com ênfase na prevenção de doenças bucais prevalentes, e consciente da necessidade de educação continuada, interagindo com a população, capaz de alterar o perfil epidemiológico de saúde bucal da região, participando do sistema de saúde, com capacidade de liderança e sensibilidade social.

O Curso de Odontologia da Universidade Federal do Pará, ressente-se de dados que possam subsidiar a elaboração de estratégias para atendimento das necessidades dos pacientes que procuram tratamento no Curso de Odontologia, pois anteriormente as disciplinas funcionavam de 
maneira estanques, utilizando fichas individuais, que dificultam o levantamento das condições de saúde bucal e necessidades de tratamento, existindo na maioria das vezes, dados relativos apenas aos procedimentos executados.

Assim, levantar as condições de saúde bucal da população residente na região e suas necessidades de tratamento, é essencial para a elaboração de estratégias adequadas, que permitam oferecer à população os tratamentos necessários a manutenção ou recuperação de sua saúde e uma adequada formação do cirurgião-dentista, tornando-o apto para atuar tanto no sistema público quanto privado. 


\section{REVISÃO DA LITERATURA}

\subsection{Curso de Odontologia da Universidade Federal do Pará}

O Curso de Odontologia da Universidade Federal do Pará, localizado no Bairro do Guamá na cidade de Belém, foi criado em 04 de julho de 1914 pela então "Sociedade Propagadora das Ciências", depois "Associação Científica do Pará", com a denominação de Escola Livre de Odontologia do Pará, substituída pela Faculdade Livre de Odontologia do Pará, por Ato da respectiva Congregação de 12 de abril de 1920. Foi encampada pelo Governo do Estado, em virtude do Decreto Lei $n^{\circ} 2.156$ de 30 de maio de 1936, com a denominação de Faculdade de Odontologia do Pará e integrada àUniversidade Federal do Pará (UFPA) pela Lei n 3.191 de 02 de julho de 1957. Tornou-se Faculdade de Odontologia da Universidade Federal do Pará em maio de 1967, transformando-se em Curso de Odontologia do Centro de Ciências da Saúde da Universidade Federal do Pará, através da Reforma de 1972, que com a Resolução n 105 de 03 de julho de 1972 aprovou o Regimento Geral da UFPA (UFPA, 2000).

O bairro do Guamá está localizado em uma área periférica da cidade de Belém, fazendo parte do Distrito das Águas, juntamente com os bairros 
da Terra Firme, Cremação, Riacho Doce (área de invasão), parte dos bairros do Jurunas e Condor, com uma população estimada em 348.716 habitantes predominantemente de baixa renda, com difícil acesso aos serviços de saúde, constituindo a maioria dos pacientes atendidos no Curso de Odontologia.

\subsection{Problemas de saúde bucal e sua epidemiologia no Brasil}

O conhecimento da situação epidemiológica da população é essencial tanto para o nível de planejamento quanto para o de execução de serviços odontológicos, constituindo-se no caminho correto de equacionamento dos problemas de saúde e doença de cada comunidade (Pinto, 2000).

O estudo da saúde e da doença nas populações enquanto condição histórica, cultural e biologicamente determinadas, em dado momento no meio social, apresenta diferentes abordagens. Algumas referem-se a uma tipificação do estado patológico, baseando-se em características intrínsecas. Outras centram-se na definição do processo, exprimindo sua identidade pela natureza coletiva, na ambientação social onde se insere o ser humano (Marcos, 1998).

No Brasil, os principais problemas de saúde bucal de relevância em saúde coletiva são: a cárie dentária, as doenças periodontais, as oclusopatias, o câncer bucal e as fendas lábio-palatinas. Entretanto, dependendo da região (fatores ligados ao lugar) em que é realizada a análise e das características do grupo populacional em estudo (fatores 
ligados a pessoa), a cárie dentária não é o principal problema e qualquer um dos outros pode ser mais prioritário e relevante do ponto de vista do significado social e sanitário (Brasil, 2000a).

Locais com altos teores de flúor presentes naturalmente em mananciais que são utilizados como fonte de abastecimento público, propiciam o aparecimento de fluorose na população infantil, que deve ser considerado também como problema de saúde pública.

Nas Universidades, cuja função primordial é a produção de conhecimentos, essa diversidade deve ser considerada e analisada, gerando informações consistentes sobre a realidade epidemiológica das doenças bucais na população brasileira a qual, nos últimos anos, começou a apresentar uma importante modificação de tendência, possibilitando assim subsídios aos sistemas de saúde para a implantação e implementação de programas de saúde voltados para a prevenção de nosologias bucais e para atender as necessidades de tratamento da população (Brasil, 2000a).

A obtenção de dados mais confiáveis em levantamentos das condições de saúde bucal e que reflitam a situação epidemiológica das comunidades, é possível quando compreende-se que levantamentos epidemiológicos são processos crescentes de experiências, onde cada experiência acrescenta e indica os detalhamentos necessários aos critérios e metodologias propostas (Sousa \& Cypriano, 2001).

Em 1956, Russel apud Belan (2000), relatou que para estabelecer as diferenças de intensidade e distribuição de uma doença ou problema é necessário recorrer-se a índices, que são valores numéricos que descrevem 
a situação relativa de uma determinada população, através de uma escala graduada com limites superior e inferior definidos, permitindo comparações com outras populações classificadas pelos mesmos métodos e critérios.

Os índices são proporções ou coeficientes que servem de indicadores da freqüência com que ocorrem determinadas doenças ou eventos na comunidade (Pizante \& Guimarães, 1997).

Em 1950 Johnson, apud Chaves (1986) afirmou que "um índice útil para a indicação do estado de saúde bucal em relação com uma doença determinada, deve preencher os seguintes critérios:

1 Pertinência - deve haver uma relação entre o índice utilizado e a doença ou condição que está sendo estudada.

2 Confiança - para que se possa ter confiança em um índice, é preciso que ele mantenha sua validade quando submetido a tratamento estatístico. As conclusões obtidas pela análise estatística devem poder ser afirmadas com determinado grau de confiança.

3 Significado - o índice deve ser capaz de despertar uma idéia compreensível, significativa, daquilo que se pretende medir."

De modo geral, os índices utilizados são de dois tipos. Uns referem simplesmente à presença ou ausência da doença, sendo utilizados para doenças de ocorrência mais ou menos rara ou de evolução rápida. Outros índices, que constituem a maioria, são os utilizados para doenças que ocorrem com grande freqüência e de evolução crônica, como a cárie dentária e as periodontopatias. Neste caso, os índices devem dar uma idéia da intensidade ou severidade da doença na comunidade (Chaves, 1986). 
Para a obtenção de dados confiáveis, é necessário realizar o processo de calibração dos examinadores envolvidos no estudo epidemiológico. Calibração consiste na padronização de critérios para 0 exame da população da amostra, para que todos os examinadores realizem os exames com o mesmo padrão de julgamento (Aboud \& Pattussi, 1998). A calibração deve ser entendida como um ponto estratégico e fundamental para que pesquisadores, técnicos e administradores do serviço público obtenham dados com um grau aceitável de uniformidade em diferentes localidades (Sousa \& Cypriano, 2001). Assim, a calibração tem por objetivo diminuir os erros intra e inter-examinadores, de maneira que se consiga reproduzir fielmente os critérios definidos para os problemas pesquisados.

Várias técnicas podem ser adotadas para o processo de calibração. As mais conhecidas são a técnica do examinador padrão e a do consenso. Autores como Sousa \& Cypriano (2001), recomendaram que seja adotada a técnica do consenso onde as discordâncias são discutidas entre os examinadores, sendo estes que definirão qual o consenso do grupo, sempre após a compreensão teórica dos critérios definidos em um momento inicial de discussão.

Brasil tem sido freqüentemente referido como um país detentor de altos índices de prevalência de doenças bucais, em particular a cárie dentária e a doença periodontal (Oliveira, 2002).

A Organização Mundial de Saúde (OMS) e Federação Dentária Internacional (FDI) recomendam æ̀s autoridades sanitárias a realização de levantamentos epidemiológicos das principais doenças bucais nas idades- 
índice de 5, 12 e 18 anos e nas faixas etárias de 35-44 e 65-74 anos numa periodicidade entre 5 a 10 anos (Aboud \& Pattussi, 1998).

A epidemiologia em saúde bucal no Brasil não apresenta dados expressivos, apesar de ter apresentado um sensível crescimento nos últimos anos, especialmente do ponto de vista da produção de dados em nível municipal (Roncalli et al., 2000). Os levantamentos epidemiológicos, ao contrário de outros países, não são realizados com freqüência, refletindo a escassez de dados de saúde bucal principalmente em nível nacional.

Somente em 1986 o Ministério da Saúde realizou o primeiro levantamento epidemiológico nacional de saúde bucal, que tinha como um dos objetivos específicos estimar a prevalência de cárie dental e das doenças periodontais, bem como a existência e necessidade de prótese total nos grupos populacionais estudados (Brasil, 1988).

Outro levantamento de nível nacional foi realizado em 1993 pelo Serviço Social da Indústria (SESI).

Um segundo levantamento epidemiológico a nível nacional foi realizado em 1996, também pelo Ministério da Saúde através da Coordenação de Saúde Bucal e em parceria com a Associação Brasileira de Odontologia Nacional, Conselho Federal de Odontologia e as Secretarias Estaduais de Saúde, demonstrando uma tendência de redução na prevalência da cárie dental no país (Furtado et al., 1999).

Dada a pouca tradição no campo da epidemiologia, as experiências nacionais foram diversas e cercadas de deficiências. São portanto, dados ruins, mas são os que temos (Oliveira, 2002). 
Assim, torna-se fundamental a necessidade de realizar estudos com a finalidade de gerar dados epidemiológicos em nível nacional, estadual e municipal, que permitam o conhecimento do processo saúde-doença da cavidade bucal, analisando a distribuição e os fatores determinantes das enfermidades, contribuindo com o estabelecimento de políticas de promoção, prevenção, controle ou tratamento, fornecendo indicadores que sirvam de suporte ao planejamento, execução e avaliação das ações de saúde bucal no Brasil (Brasil, 2000a).

\subsubsection{Cárie dentária}

A doença cárie dentária pode ser definida de várias maneiras, enfocando seus aspectos biológicos, sociais e suas conseqüências no elemento dentário. De uma maneira geral, podemos dizer que é uma doença infecciosa e multifatorial, cuja coleção de fatores que contribuem para a sua instalação e progressão, interagem modificando o equilíbrio existente entre os elementos do esmalte dentário e o meio ambiente bucal, modulado pela saliva (Medeiros, 1998).

O Índice de Ataque de Cárie, originalmente formulado em 1937 por Klein e Palmer, apud Pinto (2000), conhecido pelas iniciais CPO permanece sendo o mais utilizado em todo o mundo, mantendo-se como ponto básico de referência para o diagnóstico das condições dentais e para formulação e avaliação de programas de saúde bucal . 
Quando a unidade é o dente temos o índice CPO-D, ou seja, dentes permanentes cariados, perdidos e obturados. Quando se utiliza a unidade superfície dentária têm-se o índice CPO-S, superfícies permanentes cariadas, perdidas e obturadas. Para a dentição temporária os índices são identificados por letras minúsculas, denominando-se respectivamente ceo-d e ceo-s para índice de dentes e superfícies temporárias.

Benigeri et al. (1998), afirmaram que o ICPO-D e ICPO-S, apresentam limitações, pois consideram todos os dentes perdidos como tendo experimentado a cárie e os dentes obturados, como tendo sido cariados, dando a mesma importância a um dente cariado e um dente restaurado.

Para a medição da cárie dentária, a Organização Mundial de Saúde (OMS), preconiza atualmente a utilização do Índice de Condição Dentária e Necessidade de Tratamento (ICDNT), que funciona como uma modificação do CPO-D (dentes cariados, perdidos e obturados) tradicional. Foram acrescentadas subdivisões para o item obturado (com cárie e sem cárie) e para o perdido (por cárie e por outras razões), além de outras classificações como selante/verniz e apoio de ponte ou coroa, de onde se pode aferir o CPO-D médio para a dentição permanente e o ceo-d médio para a dentição decídua (WHO, 1997; Oliveira et al., 2003).

Para avaliar o significado dos resultados dos estudos epidemiológicos é necessário adotar uma referência para análise. Quanto mais reconhecida for a referência utilizada, tanto pelos administradores de serviços de saúde quanto pela comunidade científica, mais consistente e adequada serão a interpretação e a discussão dos resultados obtidos (Frazão, 2003). Em 
relação a cárie dentária, a classificação do ataque de cárie com base nos valores do CPO aos 12 anos de idade para determinar a prevalência de doença, estão demonstradas na Tabela 2.1.

Tabela 2.1 - Classificação do ataque de cárie com base nos valores de CPO aos 12 anos de idade

\begin{tabular}{l|c}
\hline \multicolumn{1}{c|}{ Prevalência } & CPO \\
\hline Muito Baixa & 0,0 a 1,1 \\
Baixa & 1,2 a 2,6 \\
Média & 2,7 a 4,4 \\
Alta & 4,5 a 6,5 \\
Muito Alta & $>$ ou $=6,6$ \\
\hline
\end{tabular}

Fonte: Narvai, 1996

Pereira et al. (1999), são favoráveis a uma atualização do índice CPO-S preconizado pela OMS, no que diz respeito ao diagnóstico da cárie dental e suas implicações no cálculo das necessidades de tratamento, propondo um novo índice de cárie dental baseado nas necessidades de tratamento, capaz de reconhecer as mudanças contínuas do padrão de progressão da doença, tornando-se em instrumento mais preciso para o planejamento de serviços odontológicos em Saúde Pública.

A Organização Mundial de Saúde estabeleceu como metas relativas à prevalência da cárie dentária, em diferentes idades para os anos de 2000 e 2010, os parâmetros descritos na Tabela 2.2 (São Paulo, 2003). 
Tabela 2.2 - Metas da OMS para os anos 2000 e 2010

\begin{tabular}{|c|c|c|c|c|c|}
\hline Idade & 5 a 6 anos & 12 anos & 18 anos & $35-44$ anos & $65-74$ anos \\
\hline $\begin{array}{l}\text { Metas } \\
\text { ano } \\
2000\end{array}$ & $\begin{array}{l}50 \% \text { sem } \\
\text { cárie } \\
\text { dentária }\end{array}$ & $\begin{array}{l}\text { CPO-D } \\
\text { igual ou } \\
\text { menor a } 3\end{array}$ & $\begin{array}{ll}85 \% & \text { com } \\
\text { todos } & \text { os } \\
\text { dentes } & \end{array}$ & $\begin{array}{l}75 \% \text { com } 20 \text { ou } \\
\text { mais dentes } \\
\text { presentes }\end{array}$ & $\begin{array}{l}50 \% \text { com } 20 \\
\text { ou mais } \\
\text { dentes } \\
\text { presentes }\end{array}$ \\
\hline $\begin{array}{l}\text { Metas } \\
\text { ano } 2010\end{array}$ & $\begin{array}{l}90 \% \text { sem } \\
\text { cárie } \\
\text { dentária }\end{array}$ & $\begin{array}{l}\text { CPO-D } \\
\text { igual ou } \\
\text { menor a } 1\end{array}$ & $\begin{array}{l}100 \% \text { com } \\
\text { todos os } \\
\text { dentes }\end{array}$ & $\begin{array}{l}90 \% \text { com } 20 \text { ou } \\
\text { mais dentes ou } \\
\text { até } 2 \% \text { de } \\
\text { desdentados }\end{array}$ & $\begin{array}{l}\text { Até } 5 \% \text { de } \\
\text { desdentados }\end{array}$ \\
\hline
\end{tabular}

Através do registro das necessidades de tratamento, pode-se identificar, além das necessidades propriamente ditas, a presença de lesões não cavitadas (mancha branca presente) e os diferentes níveis da doença ativa (cárie de esmalte, cárie de dentina e cárie próxima a polpa). Deste modo, uma maior qualificação do índice pode ser proporcionada pela verificação das necessidades de tratamento (Brasil, 2001).

A diminuição na prevalência de cárie começou nas décadas de 60 e 70 nos países escandinavos e Suíça, seguidos pelo Reino Unido, Irlanda e Países Baixos. A prevalência de cárie em adolescentes na Europa é similar a das crianças. Os valores de CPO-D para crianças de 12 anos mostram uma distribuição similar entre os países escandinavos, Irlanda e Suíça (1,0 a 3,0), embora em alguns países da Europa Oriental seja mais alta, como a 
Polônia que apresenta CPO-D médio de 5,1 aproximadamente (Reich, 2001).

Em 1986, foi realizado o primeiro levantamento epidemiológico de caráter nacional, pela Divisão Nacional de Saúde Bucal do Ministério da Saúde, tendo como primeiro critério de estratificação as cinco macro-regiões brasileiras. Em cada região, algumas capitais foram escolhidas para serem representativas de seus respectivos estados e, consequentemente das regiões (Brasil, 1988). Foram examinadas 22.709 pessoas, e encontrou-se como resultado um ICPO-D (Índice de dentes cariados perdidos e obturados) de 6,65 aos 12 anos; 12,69 dos 15 aos 19 anos; 24,39 dos 35 aos 44 anos e de 27,19 para a faixa etária de 50 a 59 anos para a população brasileira.

O resultado do ICPO-D aos 12 anos $(6,65)$, considerado como um dos indicadores de saúde dental internacionalmente, indicou de acordo com a escala da Organização Mundial de Saúde, uma prevalência muito alta de cárie, colocando o Brasil na ocasião com o $3^{\circ}$ pior índice do mundo, ficando atrás do Brunei e República Dominicana e empatando com a Jamaica (Oliveira, 2002).

O ICPO-D encontrado para as outras faixas etárias também foi considerado alto, com poucas diferenças em relação a faixa de renda e, com o aumento da idade, essas diminuem mais ainda, tendendo àigualdade no fim da vida (Brasil, 1988).

Quando foi comparado os problemas tratados e não-tratados, as diferenças em relação àrenda ficam marcantes. No grupo de 6-12 anos, por 
exemplo, as pessoas de renda mais baixa tinham $20 \%$ de seus dentes obturados e $67 \%$ cariados, enquanto os de renda mais alta tinham respectivamente $55 \%$ e $40 \%$, uma quase inversão do quadro epidemiológico, em função de melhores condições de vida e acesso aos serviços de saúde (Oliveira, 2002).

Em 1993, o SESI, com o objetivo de compor uma linha-base para avaliação de seus programas preventivos, realizou como parte integrante do Programa de Prevenção de Doenças Bucais, um levantamento epidemiológico em crianças das escolas do SESI, incluindo em sua amostragem algumas escolas públicas (Pinto, 1996).

Foram examinadas 110.640 crianças de 3 a 14 anos, sendo 58.450 das escolas do SESI e 52.190 das escolas públicas de 21 estados mais o Distrito Federal. Apesar de ter avaliado uma clientela "viciada", na medida em que as escolas do SESI eram diferenciadas do ponto de vista de acesso a medidas preventivas, o fato de ter tido uma abrangência nacional e de também ter avaliado escolas públicas deu, ao levantamento o critério de dado nacional na época (Oliveira, 2002). Foi encontrado o ICPO-D aos 12 anos de 4,84 o que representou uma queda de $27,2 \%$ em relação ao levantamento de 1986.

Em 1993 Maclnnis et al., realizaram um estudo em 144 freiras residentes no Convento de Mount Saint Vincent, em Halifaz, Nova Escócia. Este convento era uma residência para ambulatório e centro de saúde para os membros da ordem com problemas de saúde. Foi utilizado um índice CPO-S modificado, onde as lesões de cárie eram identificadas pela sua 
progressão. A idade média da amostra era de 77,6 anos. Delas 44 eram completamente desdentadas, 77 eram dentadas e 23 não puderam ser examinadas devido sua condição médica. A média de dentes presentes nas 77 dentadas foi de 16,7. De 60 pacientes dentadas examinadas, 59 (98,3\%) tinham pelo menos uma superfície de cárie coronal e 93,3\% tinham pelo menos uma superfície radicular cariada ou restaurada.

Com o intuito de comparar a prevalência de cárie dental no ano de 1994, com dados de um estudo prévio de 1980, na cidade de Paulínia no Estado de São Paulo, foi realizado um levantamento epidemiológico em 1.416 escolares de 7 a 14 anos, de ambos os sexos. Foi observada uma inversão dos componentes do índice CPO-D: em 1980 prevalecia o componente cariado $(69,5 \%)$, enquanto que o componente obturado prevaleceu em 1994 (79,0\%). Os componentes extraídos e a extração indicada praticamente desapareceram no ano de 1994 (Moreira et al., 1996). Aos 12 anos o CPO-D apresentou o declínio de 8,2 em 1980 para 3,0 em 1994.

A Coordenação de Saúde Bucal (COSAB) do Ministério da Saúde, realizou em 1996, o segundo levantamento epidemiológico de saúde bucal, envolvendo apenas a doença cárie dental. Foram examinados 30.240 escolares de 6 a 12 anos de escolas públicas e privadas das 27 capitais brasileiras. Os resultados mostraram um declínio de 54\% no ICPO-D aos 12 anos. De 6,65 a média do CPO-D passou para 3,06, deixando o Brasil muito próximo da meta da OMS/FDI para o ano 2000, que recomendava aos 12 anos um ICPO-D de 3,0 (Oliveira, 2001). 
No Pará, assim como na totalidade do território brasileiro, a cárie dental vem apresentando um decréscimo da incidência. No levantamento epidemiológico de saúde bucal realizado pelo Ministério da Saúde em 1986, o Pará apresentava ICPO-D de 7,7 aos 12 anos de idade. No último levantamento realizado em 1996 pelo Ministério da Saúde, observou-se a diminuição da incidência da cárie dental no Pará com um ICPO-D de 4,49.

Levantamento epidemiológico em saúde bucal realizado no Distrito Federal em 1997, onde foram realizados 8.205 exames com o objetivo de avaliar condição dental, necessidade de tratamento, fluorose e oclusopatias, mostrou um ICPO-D aos 12 anos de 2,7, com $48 \%$ das crianças aos 5 anos isentas de cárie, constatando uma baixa prevalência de cárie no Distrito Federal, com o alcance da meta da OMS para o ano 2000, em relação ao CPO-D (Aboud \& Pattussi, 1998).

Estudo realizado em 1997, em 264 crianças na faixa de 06 aos 12 anos de idade matriculadas nas escolas de Capão Alto/Santa Catarina, encontrou CPO-D médio de 2,60, com 25\% das crianças livres de cárie. Com relação aos componentes do CPO-D, os resultados demonstraram uma maior contribuição do componente cariado, com $76 \%$ do valor total do CPOD. Os componentes perdido por cárie e restaurado contribuíram com 4,1\% e 19,9\% respectivamente (Furtado et al., 1999).

Menezes (1999), ao examinar 125 pacientes em Campo Grande, divididos em 5 grupos, nas faixas etárias de 15-19 anos, 20-29 anos, 30-39 anos, 40-49 e 50-65 anos, encontrou CPO-D médio de 7,04, 13,52, 19,44, 
20,76 e 20,08 respectivamente, demonstrando um aumento do CPO-D médio com a idade.

Estudo realizado em uma amostra de 742 indivíduos no grupo etário de 35 a 44 anos por Aleksejuniene et al. (2000), na Lituânia, encontrou um ICPO-D de 14,2, demonstrando que estes indivíduos têm consideravelmente mais cárie não tratada do que tratada.

Belan (2000), examinou 200 pacientes que buscaram tratamento, pela primeira vez, na Clínica Odontológica da Faculdade de Odontologia da Universidade de São Paulo, para avaliar a condição de saúde e necessidade de tratamento da doença cárie dental e doença periodontal. Para a obtenção dos resultados, foram contabilizados 25 indivíduos na faixa etária de 15-19 anos e 43 na faixa de 35-44. Foi observado CPO-D médio de 9,39 para a faixa-etária de 15-19 anos e de 24,14 para a faixa etária de 35-44 anos. Em relação a necessidade de tratamento $52,53 \%$ dos dentes examinados não necessitavam de tratamento (36,16\% estavam hígidos e $28,77 \%$ perdidos por cárie), 4,95\% necessitavam de tratamento restaurador simples e 35,80\% necessitavam de tratamento restaurador protético (coroa, apoio de prótese e elemento de prótese).

Como parte da elaboração do Projeto das Condições de Saúde Bucal da População Brasileira no ano 2000, dois estudos pilotos foram realizados em 2000, concentrando-se as amostras nas faixas etárias de 15 a 19 anos e de 35 a 44 anos. 
O Estudo Piloto das Condições de Saúde Bucal realizado em Canela, Rio Grande do Sul (Brasil, 2000b), encontrou um ICPO-D de 5,3 para a faixa etária de 15 a 19 anos e de 22,3 para a faixa etária de 35 a 44 anos.

O Estudo Piloto das Condições de Saúde Bucal realizado em Diadema (Brasil, 2000c), encontrou um ICPO-D de 4,30 para a faixa etária de 15 a 19 anos e de 18,97 para a faixa etária de 35 a 44 anos.

Em 1998, na cidade de Blumenau/Santa Catarina, foi estudada a prevalência e severidade de cárie dentária na população de escolares a partir de uma amostra de 1.473 escolares de 6 a 12 anos, de escolas públicas e privadas, utilizando-se os critérios de diagnóstico da OMS. A prevalência de cárie na dentição permanente foi de $54,7 \%$, e o índice CPOD foi de 1,46 para as escolas públicas, com $83 \%$ apresentando um CPO-D entre 0-3,0. A baixa taxa de resposta aos 12 anos de idade em escolas privadas inviabilizou a comparação de resultados com os dados obtidos nas escolas públicas (Traebert et al., 2001).

Com a finalidade de determinar a condição de saúde oral e necessidades de tratamento de idosos de Melbourne residentes em albergues, Saub \& Evans (2001) examinaram 175 idosos com mais de 65 anos, constatando que $35,4 \%$ da amostra era dentada. O número médio de dentes presentes entre estes pacientes foi de 13,8. A média de CPO-D foi de 24,3 para os homens e 25,1 para as mulheres. A cárie radicular foi experimentada por $63,9 \%$ dos idosos dentados. $46 \%$ necessitava de pelo menos uma restauração para cárie de coroa e 30\% para cárie radicular. Menos de 20\% necessitava de extrações dentárias. 
Silva \& Maltz (2001), examinaram 1.000 escolares da rede de ensino público e particular da cidade de Porto Alegre, com o objetivo de avaliar a prevalência de cárie, gengivite e fluorose. A média de CPO-D foi de 1,63 e a fluorose foi detectada em $52,9 \%$ das crianças.

Com o objetivo de verificar a experiência de cárie dentária em escolares de 12 a 15 anos, de escolas públicas e privadas de Salvador/Bahia, Cangussu et al. (2002), examinaram 3.313 adolescentes, confirmando a redução significativa de cárie dental descrita para o Brasil em vários estudos, com um CPO-D médio aos 12 anos de 1,44 e aos 15 anos de 2,66, considerados baixos pela Organização Mundial de Saúde.

Chaise (2001), analisou 300 fichas clínicas de indivíduos de ambos os sexos de uma população urbana, sem distinção de raça e com faixa etária de 12 a 84 anos de idade, que se dirigiram ao Setor de Triagem da Faculdade de Odontologia de Passo Fundo, entre fevereiro e novembro de 1999, com o objetivo de determinar as condições de saúde bucal e necessidade de tratamento em relação a cárie dental e prótese. O CPO-D médio encontrado foi de 20,10 para todos os grupos, com média de 9,6; 16,3; 22,3; 24,2; 26,6; 26,4 e 29,7 nas faixas etárias de 12-19, 20-29, 30-39, 40-49, 50-59, 60-69 e mais de 70 respectivamente.

Para avaliar a mudança na prevalência de cárie e valores de CPO-D na população adulta de Ljubljana na Eslovênia, Kovac-Kavcic \& Skaleric (2001), realizaram um estudo longitudinal em um período de 10 anos, na população adulta, sendo encontrada uma redução no número médio de 
dentes cariados de 1,1 para 0,5, porém foi observado um aumento do CPOD $(15,9$ para 19,1$)$ devido ao aumento de dentes perdidos e obturados.

Leandrini (2002), analisou 337 fichas de indivíduos na faixa etária de 14 a 86 anos, 216 do sexo feminino e 121 do masculino, que se dirigiram a disciplina de Clínica Integrada, da Universidade Ribeirão Preto no ano de 2001. Foram observadas as condições de saúde bucal e necessidade de tratamento em relação a cárie dental e prótese. O CPO-D médio para a amostra foi de 26,01. Quando observado o CPO-D médio nas faixas etárias, foi constatado a média de 12,55 de 14-19 anos; 18,3 de 20-29 anos; 24,65 de 30-39 anos; 26,73 de 40-49 anos; 28,07 de 50-59 anos; 29,0 de 60-69 anos e 28,47 para mais de 70 anos.

Na síntese dos resultados das condições de saúde bucal do Estado de São Paulo, em 2002 (Soares et al., 2003), onde foram examinadas 16.708 pessoas de 35 municípios nas faixas etárias de 18-36 meses, 5 anos, 12 anos, 15-19 anos, 35-44 anos e 65-74 anos, foi observado o CPO-D médio de 2,5 aos 12 anos dando uma prevalência moderada de cárie. Aos 18 anos $80 \%$ da amostra apresentava todos os dentes. Na faixa etária de 35-44 anos $49 \%$ possuía 20 dentes ou mais e 11,5\% eram desdentados. De 65-74 anos de idade, $64 \%$ da população era constituída de desdentados, o que demonstrou que apenas na faixa etária de 12 anos foram atingidas as metas da OMS/FDI para o ano 2000. 


\subsubsection{Doença periodontal}

Em Periodontia, os índices são utilizados, historicamente conforme a ênfase dada a determinadas condições relativas àlocalização da afecção, à causa e ao interesse do dado. Mais precisamente são empregados, para efeito de ocorrência ou prevalência, da severidade e das necessidades de tratamento. Assim, os índices ao longo dos tempos procuram: registrar a gengivite, avaliar a destruição dos tecidos periodontais, determinar a presença de placa ou cálculo, quantificar a história da doença acumulada e expressar as necessidades de tratamento (Marcos, 1998).

Em 1973 o Índice Comunitário de Necessidades de Tratamento Periodontal (ICNTP), teve lançado suas primeiras bases. Eram utilizados três procedimentos padronizados: instrução e motivação em higiene bucal, eliminação de cálculo e indutos e cirurgia periodontal. Johansen et al. (1973), apud Belan (2000) sugeriram que as estimativas de tempo de trabalho fossem de 60 minutos para instrução de higiene e motivação em higiene bucal, 30 minutos por quadrante para eliminação de cálculo e indutos e 60 minutos por quadrante para cirurgias.

A partir de estudos promovidos pela OMS em 1978, de que participaram 14 países, para elaborar um indicador de necessidades. Em 1982, Ainamo et al. , apud Marcos (1998), descreveram o CPITN, o índice periodontal comunitário de necessidades de tratamento.

O índice foi projetado especialmente para registrar as necessidades de tratamento e não o estado periodontal. Este implicaria na determinação 
de recessão gengival e posição da margem do osso, condições que avaliam a existência de doença no passado e que não seriam influenciadas pelo tratamento (Marcos, 1998).

Linden et al. (2002), afirmaram que o CPITN não proporciona um exame periodontal detalhado, mas sim, determina uma melhor indicação de pacientes com necessidades de tratamento periodontal. Ainda, apresenta-se como um método rápido e prático para pesquisas populacionais da doença periodontal.

A instalação da periodontite é mais prevalente nos Estados Unidos que na Europa. A prevalência da doença periodontal avançada aumenta com a idade. Provavelmente, $10 \%$ dos adultos de 35-44 anos, mostram uma forma avançada de perda óssea periodontal em um ou mais dentes, $20-30 \%$ apresentam bolsa de até $5 \mathrm{~mm}$ de profundidade (doença moderada). Este valores aumentam para idosos de $30 \%$ para $60 \%$ para doença moderada (Reich, 2001).

Os dados referentes a condição de saúde e necessidade de tratamento periodontal no Brasil, à semelhança da cárie dentária e edentulismo, apresentam escassez. O levantamento epidemiológico em saúde bucal, realizado em 1986 na zona urbana do Brasil, é o único levantamento de caráter nacional existente e não contemplou a faixa etária de 12 anos, o que dificulta a comparação com os levantamentos realizados posteriormente.

Neste levantamento o estado de saúde periodontal observado através do índice CPITN, em 4.798 adolescentes examinados na faixa de 15-19 
anos foi de $53,08 \%$ de sextantes sadios, $22,34 \%$ com sangramento, $20,56 \%$ com tártaro, 2,32\% com bolsas de 4 a $5 \mathrm{~mm}, 0,18 \%$ com bolsas de 6 ou mais $\mathrm{mm}$ e $3,58 \%$ nulos para os sextantes superiores. Para os sextantes inferiores foram encontrados os seguintes percentuais: $50,29 \%$ de sextantes sadios, $19,44 \%$ com sangramento, $25,66 \%$ com tártaro, $1,95 \%$ com bolsas de 4 a $5 \mathrm{~mm}, 0,21 \%$ com bolsas de 6 ou mais $\mathrm{mm}$ e 2,34\% nulos (Brasil, 1988).

Dos 3.344 adultos examinados na faixa etária de 35-44 anos foram encontrados $16,86 \%$ de sextantes sadios, $11,46 \%$ com sangramento, 17,96\% com tártaro, $6,17 \%$ com bolsas de 4 a 5 mm, 1,49\% com bolsas de 6 ou mais $\mathrm{mm}$ e $46,0 \%$ nulos para os sextantes superiores. Para os sextantes inferiores foram encontrados os seguintes percentuais: $16,34 \%$ de sextantes sadios, $11,10 \%$ com sangramento, $29,27 \%$ com tártaro, $7,43 \%$ com bolsas de 4 a $5 \mathrm{~mm}, 1,92 \%$ com bolsas de 6 ou mais $\mathrm{mm}$ e $33,82 \%$ nulos.

Para a faixa etária de 50-59 anos, foram examinados 2.256 pacientes obtendo-se o seguinte resultado: $5,43 \%$ de sextantes sadios, $4,29 \%$ com sangramento, 8,09\% com tártaro, 4,07\% com bolsas de 4 a $5 \mathrm{~mm}, 1,74 \%$ com bolsas de 6 ou mais $\mathrm{mm}$ e $76,21 \%$ nulos para os sextantes superiores. Para os sextantes inferiores foram encontrados os seguintes percentuais: $5,58 \%$ de sextantes sadios, 5,61\% com sangramento, $15,83 \%$ com tártaro, $5,30 \%$ com bolsas de 4 a $5 \mathrm{~mm}, 2,80 \%$ com bolsas de 6 ou mais $\mathrm{mm}$ e $64,67 \%$ de sextantes nulos.

Em relação a necessidade de tratamento periodontal, observou-se que $71 \%$ das pessoas na faixa etária de $35-44$ anos precisavam realizar 
higiene oral metódica em 3,7 sextantes em média, dado aproximado do que foi encontrado no grupo de $15-19$ anos, onde $69,5 \%$ das pessoas necessitavam realizar higiene oral em 3,9 sextantes em média. Já na faixa etária de 50-59 anos apenas 49,7\% necessitavam de higiene oral devido 49,7\% da população apresentar sextantes excluídos (Brasil, 1988). As necessidades de profilaxia foram bastantes elevadas em todos os grupos, enquanto que apenas os adultos necessitavam de tratamentos cirúrgicos.

Estes dados analisados de maneira global, mostram uma elevada prevalência de doença periodontal no Brasil, porém semelhante a maioria das nações do mundo desenvolvido. Aproximadamente a metade dos brasileiros necessitavam de profilaxia e somente cerca de $7,4 \%$ das pessoas na faixa de 50 a 59 anos necessitavam de tratamento cirúrgico. Esta necessidade só não é maior em virtude da grande quantidade de perda dentária. No grupo etário de 15 a 19 anos, mais de 90\% das necessidades estão circunscritas a sangramento e cálculo (Oliveira, 2002).

Dados resultantes de dois estudos transversais representativos de saúde oral da população alemã, realizados em 1989 (n=1.741) e 1992 ( $n=1.591)$, demonstraram que 4,9\% apresentavam CPITN normal, 11,2\% apresentavam sangramento, 24,6\% apresentavam cálculo, 42,7\% bolsas de até 4 a $5 \mathrm{~mm}$ e 16,6\% bolsa de 6 ou mais $\mathrm{mm}$ para a faixa etária de 35 a 44 anos (Micheelis \& Bauch, 1996).

Saliba et al., em 1999, realizaram um estudo em uma amostra de 97 indivíduos, na faixa etária de 42 a 102 anos no município de Araçatuba em São Paulo e constataram que $71 \%$ dos sextantes eram nulos. Dos 
sextantes presentes $58 \%$ necessitavam de tratamento periodontal de higiene oral mais remoção de cálculo, $27 \%$ necessitavam de tratamento cirúrgico e 15\% de instrução de higiene apenas.

Menezes em 1999, ao examinar 125 pacientes em Campo Grande/MS, observou 15,3\% de sextantes sadios, $17,6 \%$ com sangramento a sondagem, 54,1\% com presença de cálculo, 6,7\% com presença de bolsa de 4 a $5 \mathrm{~mm}, 0,3 \%$ com bolsa de $6 \mathrm{~mm}$ ou mais e $6 \%$ de sextantes excluídos. Ao observar a necessidade de tratamento, 35\% necessitavam de melhorar a higiene bucal, 64,7\% necessitam de melhorar a higiene mais raspagem e $0,3 \%$ necessitavam de higiene, raspagem mais tratamento cirúrgico.

Belan (2000), ao examinar 183 pacientes que apresentavam sextantes válidos entre 200 pacientes, encontrou na faixa etária de 15 a 19 anos $24 \%$ dos indivíduos com sextantes hígidos, assim como $24 \%$ tanto para sextantes com sangramento a sondagem como para sextantes com presença de cálculo. $28 \%$ apresentavam sextantes com presença de bolsa entre 4 e $5 \mathrm{~mm}$ de profundidade. Na faixa etária de 33 a 44 anos, foi observado 9,30\% para sextantes hígidos como também para sextantes com sangramento a sondagem, 23,26\% apresentavam sextantes com cálculo, $37,21 \%$ sextantes com bolsa de 4 e $5 \mathrm{~mm}$ e $20,93 \%$ com bolsa de 6 ou mais mm. Quando observada a necessidade de tratamento para as duas faixas etárias estudadas, foi observado que $87,98 \%$ necessitavam de instrução em higiene, $79,23 \%$ de profilaxia e $14,21 \%$ necessitavam de cuidados complexos. 
O estudo Piloto das Condições de Saúde Bucal realizado em Canela RS (Brasil, 2000b), constatou que na faixa etária de 15 a 19 anos 29,6\% dos sextantes estavam hígidos, $29,6 \%$ com sangramento à sondagem, 30,4\% com cálculo e 9,6\% com bolsa de 4 a $5 \mathrm{~mm}$. Para a faixa etária de 35 a 44 anos $7,0 \%$ dos sextantes estavam hígidos, $7,7 \%$ com sangramento, $37,3 \%$ com cálculo, $28,2 \%$ com bolsa de 4 a $5 \mathrm{~mm}, 8,5 \%$ com bolsa de 6 ou mais $\mathrm{mm}, 10,6 \%$ sextantes estavam excluídos.

Em Diadema - SP (Brasil, 2000c), foi observado que na faixa etária de 15 a 19 anos $76,39 \%$ dos sextantes estavam hígidos, 10,16\% com sangramento àsondagem, 12,91\% com cálculo e 0,07\% com bolsa de 4 a 5 mm. Para a faixa etária de 35 a 44 anos $39,04 \%$ dos sextantes estavam hígidos, 4,30\% com sangramento, 28,52\% com cálculo, 1,85\% com bolsa de 4 a $5 \mathrm{~mm}, 0,22 \%$ com bolsa de 6 ou mais $\mathrm{mm}, 24,07 \%$ sextantes estavam excluídos.

Ajwani et al. (2001), examinaram em janeiro de 1989, 175 idosos nascidos em 1904, 1909 e 1914, que moravam em Helsinki na Finlândia, com o objetivo de verificar as condições de saúde periodontal e necessidade de tratamento, através do CPITN. O número médio de sextantes remanescentes encontrado foi de 3,7 para os homens e 3,5 para as mulheres. Tecidos periodontais saudáveis foram encontrados em $7 \%$ dos idosos. $6 \%$ dos idosos apresentaram sangramento a sondagem, $41 \%$ de tártaro ou margens salientes de restaurações. Ao todo $46 \%$ tinham bolsas periodontais profundas (34\% com bolsa de 4 a $5 \mathrm{~mm}$ e $11 \%$ com bolsa de 6 ou mais $\mathrm{mm}$ ). Quando analisada a necessidade de tratamento, $93 \%$ 
necessitavam de instrução de higiene oral, $87 \%$ de raspagem radicular e $11 \%$ de tratamento periodontal complexo (cirúrgico).

Marino et al. (2001), com o objetivo de avaliar a prevalência de doenças orais específicas em uma população vietnamita vivendo em Melbourne-Austrália, examinaram 158 vietnamitas de 18 anos ou mais. Com exceção de uma pessoa, todos mostravam sinais clínicos de gengivite. 6,4\% apresentaram sangramento a sondagem, 48,1\% apresentavam cálculo, $39,1 \%$ tinham bolsas periodontais superficiais e $5,1 \%$ bolsas com 6 ou mais mm. Apenas uma pessoa não necessitava de tratamento. A maioria necessitava de instrução de higiene, profilaxia e raspagem. Era necessário terapia periodontal complexa em cerca de $5 \%$ da amostragem.

Saub \& Evans (2001) observaram que entre 175 idosos, com mais de 65 anos, residentes em Melbourne 27,35\% dos homens e 21,4\% das mulheres apresentavam sangramento a sondagem, 54,6\% dos homens e $69,1 \%$ das mulheres apresentavam cálculo e 18,2\% dos homens apresentavam bolsa de 4 a $5 \mathrm{~mm}$. Quatro idosos não apresentaram doença periodontal. A necessidade de tratamento mais comum foi raspagem e higiene oral.

Ao examinarem 849 pacientes que visitavam pela primeira vez o hospital odontológico da Universidade de Peradeniya em Sri Lanka, com o objetivo de determinar a necessidade e exigência de tratamento dentário, Ekanayake et al. (2001) concluíram que a predominância da necessidade de tratamento foi para a doença periodontal com $77 \%$ enquanto $47 \%$ necessitavam de restaurações ou extrações. 
Corbert et al. (2001), com o propósito de descrever as condições periodontais em adultos chineses do sul e investigar os fatores que podem influenciar a perda de inserção periodontal, examinaram 1.572 indivíduos de 35 a 44 anos e 1.286 de 65 a 74 anos de idade através do CPITN. 61-68\% dos adultos na faixa de 35-44 anos e 54-57\% na faixa de 65-74 anos apresentavam cálculo. Um terço da população examinada apresentava bolsas superficiais e 3-7\% apresentava bolsas profundas.

Em estudo realizado por Meneghim et al. (2002), onde foram examinados 151 indivíduos pertencentes a uma população institucionalizada na cidade de Piracicaba - São Paulo, de ambos os sexos com idade entre 50 e 75 anos de idade num grupo e de com mais de 75 anos no segundo grupo, verificou-se que $90,5 \%$ de sextantes estavam excluídos no grupo de $50-75$ anos e $97,2 \%$ nos idosos com mais de 75 anos. Do total de sextantes válidos, a faixa etária de 50 a 75 anos apresentou 30,4\% classificados como hígidos, 19,7\% apresentaram sangramento gengival, 32,1\% cálculo e 17,8\% bolsa periodontal. Para a faixa etária de mais de 75 anos, 66,7\% foram classificados como hígidos, 22,2\% apresentavam sangramento à sondagem e $11,1 \%$ apresentavam cálculo. Quando analisada a necessidade de tratamento, foi observado que para a faixa etária de 50-75 anos, 19,7\% dos sextantes necessitavam de instruções de saúde bucal, 42,8\% de raspagem periodontal, enquanto $7,15 \%$ dos sextantes necessitavam de tratamento complexo. Para a faixa etária de mais de 75 anos, a maior porcentagem dos sextantes válidos $(66,7 \%)$ não necessitavam de tratamento, 22,2\% dos 
sextantes necessitavam de instruções de saúde bucal e $11,1 \%$ de raspagem periodontal.

A síntese dos resultados das condições de saúde bucal do Estado de São Paulo, realizada em 2002 (Soares et al., 2003), constatou que aos 12 anos $17 \%$ das crianças já apresentavam sangramento gengival e 14\% apresentavam cálculo dental, sendo que percentuais semelhantes foram observados nos adolescentes de 15 a 19 anos (17\% com sangramento gengival e 19\% com cálculo dental).

Nos adultos, apenas $29,9 \%$ não apresentavam problemas periodontais, enquanto aos 12 e 15 a 19 anos, respectivamente, 65,8\% e $63,9 \%$ não apresentavam problemas periodontais. Na faixa etária de 35 a 44 anos, a maioria das pessoas $(38,2 \%)$ tinha a presença de cálculo como pior condição; para os idosos predominaram os sextantes nulos (São Paulo, 2003).

\subsubsection{Edentulismo}

O Índice de Uso e Necessidades de Prótese segue a orientação da OMS (1999) para levantamentos epidemiológicos, permitindo a comparação histórica e atendendo às necessidades de planejamento específicas desta área.

Os últimos dados referentes a uso e necessidade de prótese no Brasil, datam de 1986, quando da realização do levantamento epidemiológico de saúde bucal do Brasil. O uso e a necessidade de prótese 
foi baseada na presença ou necessidade de prótese total. Nada menos que $72 \%$ da população urbana analisada, na faixa de 50 a 59 anos, tinha extraído todos os dentes de pelo menos um maxilar. Nesse grupo, $14 \%$ necessitavam colocar um aparelho protético e $45 \%$ já o possuíam, enquanto $11 \%$ encontravam-se numa posição mista, com presença de prótese superior e ausência de inferior. Somente $23 \%$ das pessoas desse grupo mantinha seus dentes numa condição tal, que permitia evitar o recurso extremo da prótese total. No grupo de 35 a 44 anos, quatro em cada dez pessoas necessitavam de tratamento protético, reduzindo-se esta proporção a 1,7\% na faixa de 15 a 19 anos, no país (Brasil, 1988).

Rosa et al. (1993), realizaram um estudo epidemiológico em 257 pessoas com 60 anos ou mais - considerados idosos funcionalmente independentes, parcialmente dependentes e totalmente dependentes. Os dados referentes ao uso de prótese foram de que $47 \%$ dos idosos usavam prótese total e $6 \%$ parcial na maxila, $31 \%$ e $6 \%$ para a mandíbula respectivamente. Quando analisada a necessidade de prótese constatou-se que $38 \%$ necessitavam de prótese total para a maxila e $48 \%$ para a mandíbula e $5 \%$ de prótese parcial para a maxila e 10\% para a mandíbula.

Maclnnis et al. (1993), realizaram estudo em 117 freiras residentes no Convento de Mount Saint Vincent, em Halifaz, Nova Escócia e constataram que 96 usavam pelo menos um aparelho protético. $55 \%$ de todas as próteses eram não retentivas, $20 \%$ precisavam de substituição e $17 \%$ precisavam de reparos ou ajustes pequenos. Apesar de $80 \%$ das 
residentes expressarem satisfação com suas próteses, as restantes desejavam substituí-las.

Ao levantar as necessidades protéticas de 1107 pacientes com idade a partir de 15 anos que procuraram atendimento na Universidade Central da Venezuela, Sanchez et al. (1998), constataram que 68,9\% necessitavam de algum tipo de tratamento protético, com predominância na faixa etária de 25 a 54 anos. As próteses parciais (76,1\%) abrangem a maior parte da demanda e 23,9\% necessitam de próteses totais.

Meneghim et al. (2000) examinaram 209 pessoas a partir de 45 anos, no município de Piracicaba - São Paulo, com o objetivo de verificar as condições de saúde bucal da população idosa deste município. Nos dados referentes a necessidade de prótese, foi observada uma necessidade de prótese total reduzida, em todas as idades, variando de $1,44 \%$ a $3,83 \%$ no arco superior e inferior, respectivamente. A pouca necessidade de prótese pode estar ligada ao fato de $65,55 \%$ dos pacientes já usarem prótese total no arco superior e $36,36 \%$ no arco inferior e que a OMS não estabelece padrões exatos para as próteses utilizadas serem consideradas aceitáveis ou não. Dos sujeitos examinados, 125 pessoas $(59,81 \%)$ não necessitavam de prótese superior e inferior, enquanto 37 pessoas $(17,70 \%)$ não usavam nenhum tipo de prótese.

O Estudo Piloto das Condições de Saúde Bucal realizado em Canela (Brasil, 2000b), constatou o uso de prótese superior em 2,2\% da amostra na faixa etária de 15 a 19 anos e de $60,6 \%$ para a faixa etária de 35 a 44 anos. Em relação ao uso de prótese inferior os dados encontrados foram 
de $12 \%$ para a faixa de 35 a 44 anos e $0 \%$ para de 15 a 19 anos. Necessitavam de prótese superior 8,9\% dos pacientes na faixa etária de 15 a 19 anos e $38,0 \%$ de 35 a 44 anos. A necessidade de prótese inferior foi de $24,4 \%$ e $78,9 \%$ para as faixas etárias de 15 a 19 e 35 a 44 anos respectivamente.

Em Diadema (Brasil, 2000c), 1,29\% dos pacientes de 15 a 19 anos usavam prótese e $51,06 \%$ de 35 a 44 anos. Em relação a necessidade de prótese $12,67 \%$ e $67,12 \%$ dos indivíduos examinados nas faixas etárias de 15 a 19 e 35 a 44 anos respectivamente, necessitavam de algum tipo de prótese.

Estudo realizado por Scelza et al. (2001), em 103 pacientes com idade superior a 60 anos, pertencentes ao Programa Interdisciplinar de Geriatria e Gerontologia da Universidade Federal Fluminense , para verificar o índice CPO-D e utilização de próteses total e parcial, constatou que em relação a próteses parciais $11,1 \%$ das mulheres e $4,5 \%$ dos homens usavam próteses superiores e 14,8\% das mulheres e 13,65\% dos homens usavam próteses parciais inferiores. No tocante as próteses totais, $77,8 \%$ das mulheres e $54,5 \%$ dos homens utilizavam próteses superiores, 38,3\% e $13,6 \%$ próteses totais inferiores eram utilizadas pelas mulheres e homens, respectivamente.

Chaise (2001), ao analisar 300 fichas clínicas de indivíduos de ambos os sexos de uma população urbana, sem distinção de raça e com faixa etária de 12 a 84 anos de idade em Passo Fundo, no ano 1999, constatou em relação ao uso de prótese que $66 \%$ dos pacientes avaliados não usavam 
prótese enquanto que 34\% faziam uso de prótese parcial (fixa ou removível) ou total. Quando analisada a necessidade de prótese, 35\% dos pacientes necessitavam de próteses parciais superiores, $49 \%$ de próteses parciais inferiores, $16 \%$ de próteses totais superiores e 5,7\% de próteses totais inferiores.

Saub \& Evans (2001), encontraram 148 idosos, do total de uma amostra de 175, usando dentaduras durante o exame clínico. Dois não possuíam dentadura e um desdentado possuía apenas prótese superior. Entre os dentados, 23 não tinham dentadura e 26 tinham dentadura completa ou parcial. $50 \%$ não tinham necessidade de tratamento protético. Eram necessárias novas dentaduras totais inferiores para $16 \%$ da amostra e $18 \%$ necessitavam de ajustes nas dentaduras totais inferiores e reparos de quebras.

Leandrini (2002), observou que $14,83 \%$ dos 337 pacientes estudados não utilizavam prótese, enquanto que $85,16 \%$ faziam uso de prótese parcial (fixa ou parcial) ou total. A prótese total $(52,86 \%)$ foi a mais freqüente seguida por prótese parcial fixa (34,92\%) e por prótese removível $(33,82 \%)$. Em relação a necessidade de prótese, 35,01\% dos pacientes necessitavam de próteses parciais superiores, $74,73 \%$ de próteses parciais inferiores, $48,61 \%$ de próteses totais superiores e $15,17 \%$ de próteses totais inferiores.

Estudo realizado por Moimaz et al. (2002), em uma amostra de 1.157 adultos residentes na região noroeste do Estado de São Paulo, concluiu que 1,04\% de indivíduos aos 18 anos, 48\% na faixa de 35-44 anos e 69,93\% na faixa de 65-74 anos, faziam uso de prótese. Em relação a necessidade de 
prótese, os dados encontrados foram: $9,3 \%$ aos 18 anos, 48,68\% de $35-44$ anos e $51,65 \%$ de $65-74$ anos.

O levantamento das condições de saúde bucal do Estado de São Paulo, em 2002 (São Paulo, 2003), demonstrou que em relação ao uso de prótese dentária, mais de 92,0\% dos jovens não utilizavam prótese, 37,2\% dos adultos as utilizavam na arcada superior e 16,4\% na arcada inferior. $76,1 \%$ dos idosos usavam prótese superior e 52,1\% usavam na arcada inferior. 


\section{PROPOSIÇÃO}

Avaliar as condições de saúde bucal e necessidades de tratamento em Cárie Dentária, Doença Periodontal e Prótese, dos pacientes que procuram atendimento no Curso de Odontologia da Universidade Federal do Pará. 


\section{MATERIAL E MÉTODOS}

\subsection{Material}

\subsubsection{Instrumental}

Foi utilizado o instrumental clínico abaixo relacionado, em pacotes individuais, dentro das normas de biossegurança previstas pelo Ministério da Saúde:

- Espelho clínico plano oㅜ 5 Duflex

- Pinça clínica Duflex

- Sonda periodontal CPI (índice periodontal comunitário), Trinity

\subsubsection{Equipamento}

- Equipamentos odontológicos completos, das clínicas do Curso de Odontologia da Universidade Federal do Pará

- Microcomputador Duron 1.1 GHZ, HD20GB, 120 MD

- Autoclave 19 litros Dabi-Atlante

\subsubsection{Outros materiais}

- Fichas clínicas (Apêndice 1) 
- Fichas para autorização de exame e divulgação de trabalhos científicos (Apêndice 2)

- Caneta, prancheta, lápis e borracha

- Material de biossegurança: gorro, máscaras, óculos, luvas para procedimentos descartáveis, avental, filme de PVC e papel alumínio - Guardanapo de papel

\subsection{Métodos}

Os pacientes selecionados para o estudo seguiram as normas estabelecidas para atendimento no Curso de Odontologia da Universidade Federal do Pará, ou seja, após cadastrados no Serviço Social foram encaminhados para a Triagem onde foram atendidos pela examinadora que, após explicar o objetivo do trabalho, procedia a solicitação da autorização do paciente ou responsável para a realização do exame clínico e divulgação de dados obtidos em trabalhos científicos, conforme orientação da Comissão de Bioética do Curso de Odontologia da UFPA na autorização para realização do trabalho (Anexo 1). Após a autorização de procedimento, eram coletados os dados para identificação do paciente e realizado o exame clínico para registro das condições de saúde bucal, de acordo com as especificações abaixo relacionadas:

\subsubsection{Nome}

\subsubsection{Endereço}

4.2.3 Idade: expressa através do número de anos correspondente a data do último aniversário 
4.2.4 Sexo: masculino e feminino

4.2.5 Grupo étnico: determinado de acordo com padronização do Ministério da Saúde para o Levantamento das Condições de Saúde Bucal da População Brasileira do ano 2000: amarelo, branco, negro, pardo, indígena e sem registro (quando não foi possível determinar o grupo étnico)

4.2.6 Número do documento de identidade: número da carteira de identidade, cadastro de pessoa física ou carteira de trabalho

4.2.7 Data da última visita ao dentista: tempo decorrido em anos correspondente ao último tratamento realizado

A seguir era iniciado o exame clínico para levantamento das condições de saúde bucal e necessidades de tratamento em cárie dental, doença periodontal e uso e necessidade de prótese, com o auxílio de um anotador devidamente orientado.

A examinadora foi treinada para realização dos exames durante o Estudo Piloto no município de Canelas - Rio Grande do Sul, realizado pelo Ministério da Saúde em 2000, como parte integrante do Projeto SB 2000, para levantar as condições de saúde bucal da população brasileira.

Os exames foram realizados utilizando-se espelho bucal plano e sonda específica, preconizada pela Organização Mundial de Saúde, denominada sonda CPI (Índice Periodontal Comunitário), com esfera de 0,5 $\mathrm{mm}$ na ponta e área anelada em preto situada entre 3,5 e 5,5 $\mathrm{mm}$ da ponta. Outras duas marcas na sonda, permitem identificar distâncias de $8,5 \mathrm{~mm}$ e $11,5 \mathrm{~mm}$ da ponta do instrumento (Figura 4.1). 


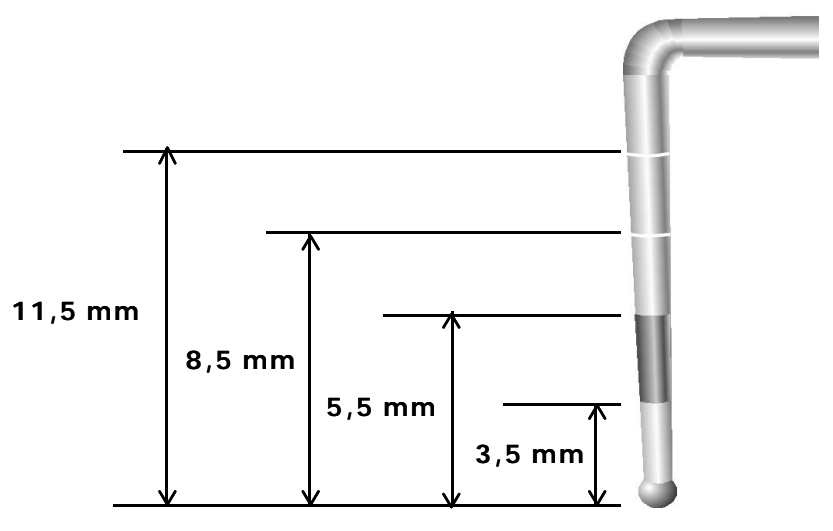

Figura 4.1 - Sonda CPI, ilustrando as marcações com as distâncias, em milímetros, àponta da sonda. Adaptado Brasil, 2001

A seqüência de exames foi padronizada, iniciando-se pelo Índice do Uso e Necessidade de Prótese Dentária, onde era observado inicialmente a utilização de prótese dentária no arco superior e posteriormente no inferior, seguindo-se da determinação da necessidade de prótese na mesma seqüência.

\subsection{8 Índice do uso e necessidade de prótese}

A situação quanto às próteses dentárias foi avaliada a partir de informações sobre seu uso e necessidade, os quais têm como base a presença de espaços protéticos. Um mesmo indivíduo pode estar usando e, ao mesmo tempo, necessitar de prótese.

Para codificar o uso e necessidade de prótese foram observados durante o exame clínico os critérios expostos nas Figuras 4.2 e 4.3 a seguir: 


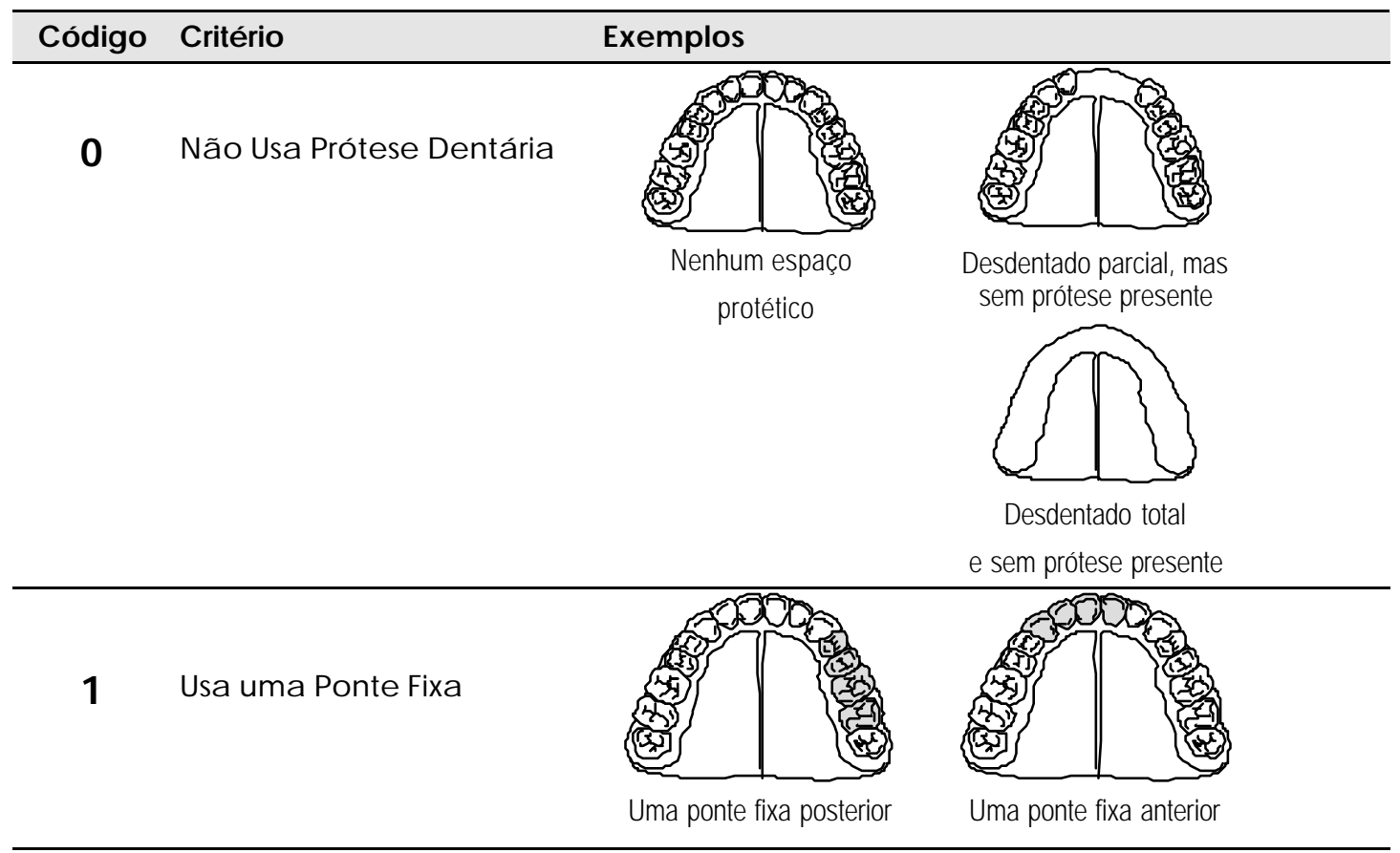

2 Usa mais do que uma

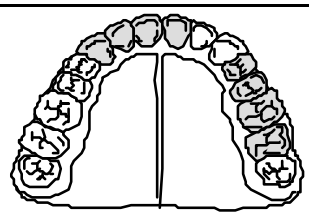

Duas pontes fixas em pontos diferentes (anterior e posterior)

3 Usa Prótese Parcial

Prótese Parcial Removível anterior

Usa uma ou mais pontes

4 fixas e uma ou mais removíveis

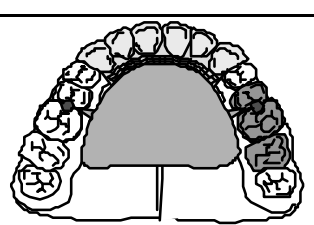

Prótese removível anterior ponte fixa posterior

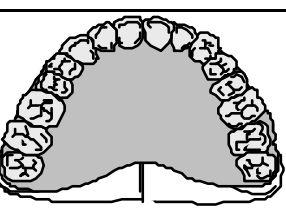

Prótese total

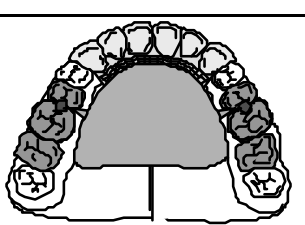

Prótese removível anterior $e$ duas pontes fixas posteriores

5 Usa Prótese Dentánia Total

9 Sem Informação

Fonte: Brasil, 2001

Figura 4.2 - Códigos para uso de prótese 


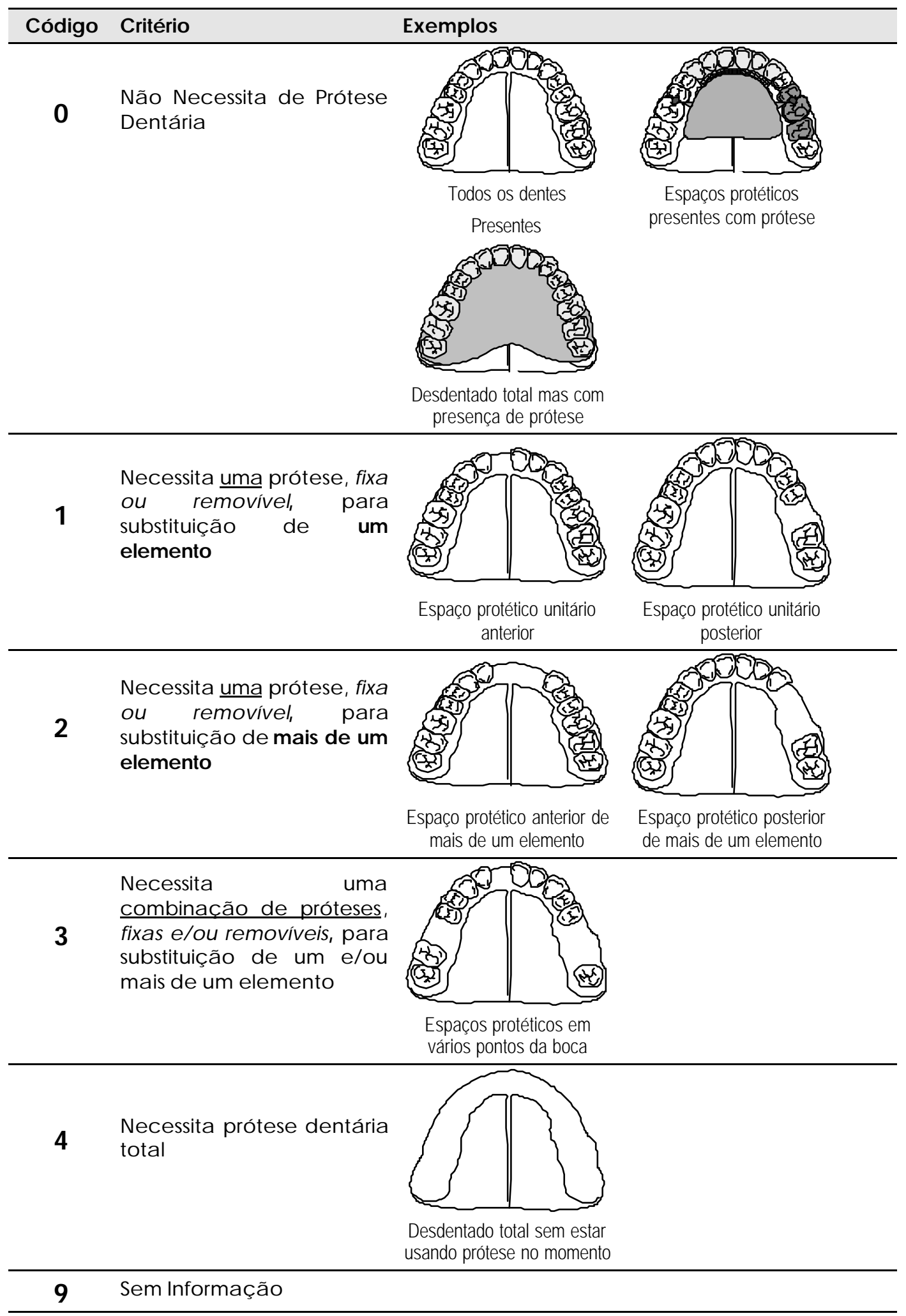

Fonte: Brasil, 2001

Figura 4.3 - Códigos para necessidade de prótese 
Logo após, era realizado o Índice de Condição Dentária para coroa e raiz e Necessidade de Tratamento. Os diferentes espaços dentários eram abordados de um para outro, sistematicamente, iniciando do terceiro molar até o incisivo central do hemiarco superior direito (18 ao 11), passando em seguida ao incisivo central esquerdo até o terceiro molar esquerdo (21 ao 28), indo para o hemiarco inferior esquerdo (38 ao 31) e, concluindo com o hemiarco inferior direito (41 ao 48), observando-se os critérios descritos a seguir e nos Quadros 4.1 e 4.2.

4.2.9 Índice de condição dentária e necessidade de tratamento:

Preconizado pela OMS (1999), com o objetivo de detalhar a situação de cárie dentária na coroa e raiz, com as necessidades de tratamento do paciente.

Foram avaliados três aspectos em cada espaço dentário: as condições da coroa e da raiz e a necessidade de tratamento.

Os códigos e critérios utilizados de acordo com o preconizado em Brasil (2001), foram os seguintes (para decíduos entre parênteses):

\section{O(A) - Coroa hígida}

Não há evidência de cárie. Estágios iniciais da doença não são levados em consideração. Os seguintes sinais devem ser codificados como hígidos:

- manchas esbranquiçadas; 
- descolorações ou manchas rugosas resistentes à pressão da sonda $\mathrm{CPI}$;

- sulcos e fissuras do esmalte, manchados mas que não apresentam sinais visuais de base amolecida, esmalte socavado, ou amolecimento das paredes, detectáveis com a sonda CPI;

- áreas escuras, brilhantes, duras e fissuradas do esmalte de um dente com fluorose moderada ou severa.

- lesões que, com base na sua distribuição ou história, ou exame táctil/visual, resultem de abrasão.

Raiz Hígida. A raiz está exposta e não há evidência de cárie ou de restauração (raízes não expostas são codificadas como "8").

Observação: Todas as lesões questionáveis devem ser codificadas como dente hígido.

\section{1(B) - Coroa cariada}

Sulco, fissura ou superfície lisa apresenta cavidade evidente, ou tecido amolecido na base ou descoloração do esmalte ou de parede ou há uma restauração temporária (exceto ionômero de vidro).

\section{Raiz cariada}

Lesão pode ser detectada com a sonda CPI. Se há comprometimento radicular discreto, produzido por lesão proveniente da coroa, a raiz só é considerada cariada se há necessidade de tratamento radicular em separado. 


\section{2(C) - Coroa restaurada mas cariada}

Há uma ou mais restaurações e ao mesmo tempo uma ou mais áreas estão cariadas.

\section{Raiz restaurada mas cariada}

Idem coroa restaurada mas cariada. Em situações onde coroa e raiz estão envolvidas, a localização mais provável da lesão primária é registrada como restaurada mas cariada. Quando não é possível avaliar essa probabilidade, tanto a coroa quanto a raiz são registradas como restauradas mas com cárie.

\section{3(D) - Coroa restaurada e sem cárie}

Há uma ou mais restaurações definitivas e inexiste cárie primária ou recorrente. Um dente com coroa colocada devido à cárieinclui-se nesta categoria. Se a coroa resulta de outras causas, como suporte de prótese, é codificada como $7(\mathrm{G})$.

\section{Raiz restaurada e sem cárie}

Idem coroa restaurada e sem cárie.

\section{4(E) - Dente perdido devido à cárie}

Um dente permanente ou decíduo foi extraído por causa de cárie e não por outras razões. Essa condição é registrada na casela correspondente à coroa. Dentes decíduos: aplicar apenas quando o 
indivíduo está numa faixa etária na qual a esfoliação normal não constitui justificativa suficiente para a ausência.

Nesses casos o código registrado na casela correspondente àraiz é 9 ou 7 (quando tiver um implante no lugar). Em algumas idades pode ser difícil distinguir entre dente não irrompido (código 8) e dente perdido (códigos 4 ou 5). Fazer relações (cronologia da erupção, experiência de cárie etc.) pode ajudar na tomada de decisão.

\section{$5(F)$ - Dente perdido por outra razão}

Ausência se deve a razões ortodônticas, periodontais, traumáticas ou congênitas.

\section{6(G) - Selante}

Há um selante de fissura ou a fissura oclusal foi alargada para receber um compósito. Se o dente possui selante e está cariado, prevalece o código 1 ou B (cárie).

\section{7(H) - Apoio de ponte ou coroa}

Indica um dente que é parte de uma prótese fixa. Este código é também utilizado para coroas instaladas por outras razões que não a cárie ou para dentes com facetas estéticas. Dentes extraídos e substituídos por um elemento de ponte fixa são codificados, na casela da condição da coroa, como 4 ou 5, enquanto o código 9 deve ser lançado na casela da raiz. 
Implante: Registrar este código (7) na casela da raiz.

\section{8(K) - Coroa não erupcionada}

Quando o dente permanente ou decíduo ainda não foi erupcionado, atendendo à cronologia da erupção. Não inclui dentes perdidos por problemas congênitos, trauma etc.

\section{Raiz não exposta}

Não há exposição da superfície radicular, isto é, não há retração gengival para além da junção cemento-esmalte.

\section{$T(T)$ - Trauma (Fratura)}

Parte da superfície coronária foi perdida em conseqüência de trauma e não há evidência de cárie.

\section{9(L) - Dente Excluído}

Aplicado a qualquer dente permanente que não possa ser examinado (bandas ortodônticas, hipoplasias severas etc.). 
Quadro 4.1- Códigos para condição de cárie dentária

\begin{tabular}{|c|c|c|c|}
\hline \multicolumn{3}{|c|}{ CÓDIGO } & \multirow{3}{*}{ CONDIÇÃO/ESTADO } \\
\hline \multirow{2}{*}{$\begin{array}{c}\text { DENTES } \\
\text { DECÍDUOS } \\
\text { Coroa }\end{array}$} & \multicolumn{2}{|c|}{$\begin{array}{c}\text { DENTES } \\
\text { PERMANENTES }\end{array}$} & \\
\hline & Coroa & Raiz & \\
\hline$A$ & 0 & 0 & HÍGIDO \\
\hline$B$ & 1 & 1 & CARIADO \\
\hline C & 2 & 2 & RESTAURADO MAS COM CÁRIE \\
\hline $\mathrm{D}$ & 3 & 3 & RESTAURADO E SEM CÁRIE \\
\hline$E$ & 4 & $\begin{array}{l}\text { Não se } \\
\text { aplica }\end{array}$ & PERDIDO DEVIDO À CÁRIE \\
\hline $\mathrm{F}$ & 5 & $\begin{array}{l}\text { Não se } \\
\text { aplica }\end{array}$ & PERDIDO POR OUTRAS RAZÕES \\
\hline G & 6 & $\begin{array}{l}\text { Não se } \\
\text { aplica }\end{array}$ & APRESENTA SELANTE \\
\hline $\mathrm{H}$ & 7 & 7 & APOIO DE PONTE OU COROA \\
\hline $\mathrm{K}$ & 8 & 8 & $\begin{array}{l}\text { NÃO ERUPCIONADO - RAIZ NÃO } \\
\text { EXPOSTA }\end{array}$ \\
\hline $\mathrm{T}$ & $\mathrm{T}$ & $\begin{array}{l}\text { Não se } \\
\text { aplica }\end{array}$ & TRAUMA (FRATURA) \\
\hline $\mathrm{L}$ & 9 & 9 & DENTE EXCLUÍDO \\
\hline
\end{tabular}

Fonte: Brasil, 2001

Os códigos e critérios para as necessidades de tratamento foram:

\section{0 - Nenhum tratamento}

A coroa e a raiz estão hígidas, ou o dente não pode ou não deve ser extraído ou receber qualquer outro tratamento.

1 - Restauração de uma superfície dentária

2 - Restauração de duas ou mais superfícies dentárias

3 - Coroa por qualquer razão

4 - Faceta estética 


\section{5 - Tratamento pulpar e restauração}

O dente necessita tratamento endodôntico previamente à colocação da restauração ou coroa, devido àcárie profunda e extensa, ou mutilação ou trauma.

\section{6 - Extração}

Um dente é registrado como "indicado para extração", dependendo das possibilidades de tratamento disponíveis, quando:

- a cárie destruiu o dente de tal modo que não é possível restaurá-lo;

- a doença periodontal progrediu tanto que o dente está com mobilidade, há dor ou o dente está sem função e, no julgamento clínico do examinador, não pode ser recuperado através de tratamento periodontal;

- um dente precisa ser extraído para confecção de uma prótese; ou,

- a extração é necessária por razões ortodônticas ou estéticas, ou devido àimpactação.

\section{7 - Remineralização de mancha branca}

\section{8 - Selante}

A indicação de selantes de fóssulas e fissuras não é uma unanimidade entre os cirurgiões-dentistas, havendo profissionais que não o indicam em nenhuma hipótese. Nesta pesquisa a necessidade de selante será registrada. Sua indicação, conforme regra de decisão adotada pela 
Faculdade de Saúde Pública da Universidade de São Paulo, será feita na presença simultânea das seguintes condições:

- o dente está presente na cavidade bucal há menos de 2 (dois) anos;

- o dente homólogo apresenta cárie ou foi atingido pela doença;

- há presença de placa clinicamente detectável evidenciando higiene bucal precária.

Quadro 4.2 - Códigos para necessidade de tratamento de cárie dentária

\begin{tabular}{|c|l||}
\hline CÓDIGO & \multicolumn{1}{|c|}{ TRATAMENTO } \\
\hline 0 & NENHUM \\
1 & RESTAURAÇÃO DE 1 SUPERFÍCIE \\
2 & RESTAURAÇÃO DE 2 OU MAIS SUPERFÍCIES \\
3 & COROA POR QUALQUER RAZÃO \\
4 & FACETA ESTÉTICA \\
5 & PULPAR + RESTAURAÇÃO \\
6 & EXTRAÇÃO \\
7 & REMINERALIZAÇÃO DE MANCHA BRANCA \\
8 & SELANTE \\
9 & SEM INFORMAÇÃO \\
\hline
\end{tabular}

Fonte: Brasil, 2001

Em seguida era realizado o exame para diagnóstico das condições periodontais, através do Índice de CPITN.

4.2.10 Índice periodontal comunitário de necessidades de tratamento

O Índice Periodontal Comunitário (emprega-se a sigla CPI, das iniciais do índice em inglês, pela facilidade fonética e pela sonoridade próxima ao 
consagrado CPO - cariados, perdidos e obturados) permite avaliar a condição periodontal quanto àhigidez, sangramento, e presença de cálculo ou bolsa.

A boca é dividida em sextantes definidos pelos dentes: 18-14, 13-23, 24-28, 38-34, 33-43 e 44-48 (Figura 4.4). A presença de dois ou mais dentes sem indicação de exodontia (por exemplo comprometimento de furca, mobilidade etc), é pré-requisito ao exame do sextante. Sem isso, o sextante é cancelado (quando há, por exemplo, um único dente presente). Não se considera o terceiro molar na contagem de dentes presentes no sextante, na faixa etária de 15 a 19 anos. Caso se detecte a presença de um dente e o terceiro molar nesta faixa etária, o sextante será excluído.

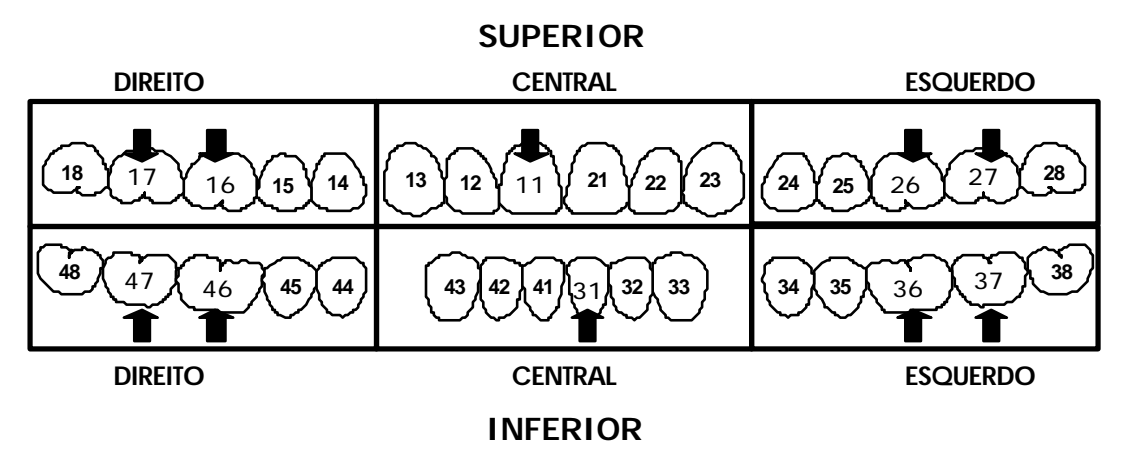

Figura 4.4 - Divisão da arcada em sextantes e destaque dos dentes-índices para CPI. Adaptado Brasil, 2001

Para o exame são os seguintes os dentes-índices para cada sextante (se nenhum deles estiver presente, examinam-se todos os dentes remanescentes do sextante, não se levando em conta a superfície distal dos terceiros molares): 
- Até 19 anos: $16,11,26,36,31$ e 46.

- 20 anos ou mais: $17,16,11,26,27,37,36,31,46$ e 47.

Pelo menos 6 pontos são examinados em cada um dos 10 dentesíndices, nas superfícies vestibular e lingual, abrangendo as regiões mesial, média e distal. Os procedimentos de exame devem ser iniciados pela área disto-vestibular, passando-se para a área média e daí para a área mésiovestibular. Após, inspeciona-se as áreas linguais, indo de distal para mesial. A sonda deve ser introduzida levemente no sulco gengival ou na bolsa periodontal, ligeiramente inclinada em relação ao longo eixo do dente, seguindo a configuração anatômica da superfície radicular. Movimentos de vai-e-vem vertical, de pequena amplitude devem ser realizados.

Ao proceder os registros dos dados das condições periodontais foram observadas as seguintes orientações de acordo com a OMS ( 1999):

1- em crianças com menos de 15 anos (portanto, na idade de 12 anos) não são feitos registros de bolsas (códigos 3 e 4), uma vez que as alterações de tecidos moles podem estar associadas à erupção e não àpresença de alteração periodontal patológica;

2- embora 10 dentes sejam examinados, apenas 6 anotações são feitas: uma por sextante, relativa àpior situação encontrada;

3- quando não há no sextante pelo menos dois dentes remanescentes e não indicados para extração, cancelar o sextante registrando um "X". 
São os seguintes os códigos utilizados no CPI (Figura 4.5 e Quadro 4.3):

0 - sextante hígido.

1 - sextante com sangramento (observado diretamente ou com espelho, após sondagem).

2 - cálculo (qualquer quantidade mas com toda a área preta da sonda visível).

3 - bolsa de 4 a 5 mm (margem gengival na área preta da sonda).

4 - bolsa de 6 mm ou mais (área preta da sonda não está visível).

X - sextante excluído (menos de 2 dentes presentes).

9 - sextante não examinado.
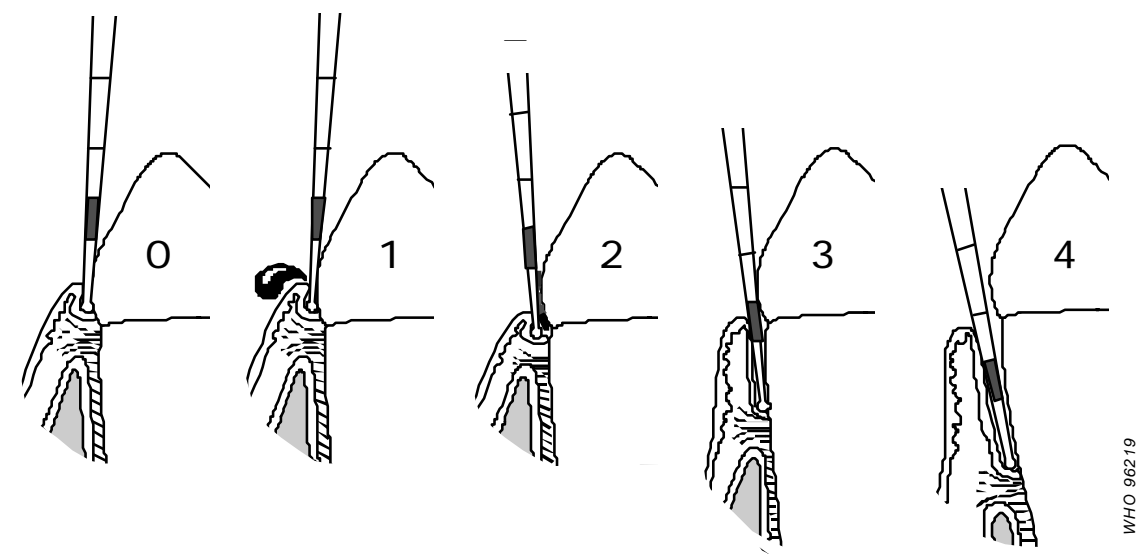

Figura 4.5 - Codificação do Índice Periodontal Comunitário (CPI), ilustrando a posição da sonda para o exame. Adaptado Brasil, 2001 
Quadro 4.3 - Códigos para condição periodontal

\begin{tabular}{|c||l||}
\hline Código & \multicolumn{1}{|c|}{ Condição/Estado } \\
\hline $\mathbf{0}$ & Sextante hígido \\
$\mathbf{1}$ & Sextante com sangramento \\
$\mathbf{2}$ & Cálculo \\
$\mathbf{3}$ & Bolsa de 4 a 5 mm (margem gengival na área preta da sonda) \\
$\mathbf{4}$ & Bolsa de 6 mm ou mais (área preta da sonda não está visível) \\
$\mathbf{X}$ & Sextante excluído \\
$\mathbf{9}$ & Sextante não examinado \\
\hline
\end{tabular}

Fonte: Brasil, 2001

Determinadas as condições de saúde periodontal, a necessidade de tratamento era definida de acordo com o demonstrado no quadro 4.4.

Quadro 4.4 - Códigos para necessidade de tratamento periodontal

\begin{tabular}{|c|l||}
\hline Código & \multicolumn{1}{|c|}{ Tratamento } \\
\hline \hline $\mathbf{0}$ & Nenhum \\
$\mathbf{1}$ & Educação em saúde \\
$\mathbf{2}$ & Profilaxia + educação \\
$\mathbf{3}$ & Raspagem radicular + profilaxia + educação \\
$\mathbf{4}$ & Cirurgia + raspagem radicular + profilaxia +educação \\
\hline
\end{tabular}




\subsection{Metodologia de avaliação}

O estudo foi desenvolvido dentre os pacientes que procuraram pela primeira vez a Clínica do Curso de Odontologia da Universidade Federal do Pará ou que ainda não tinham realizado o tratamento odontológico, durante os meses de março a maio de 2002. A Clínica do Curso atende aproximadamente 330 casos novos por mês. Foram selecionados 120 pacientes, de ambos os sexos, em uma amostra aleatória simples, de acordo com o comparecimento ao Serviço Social para iniciar o tratamento odontológico, com as seguintes idades: 12 , 15 a 19 ,35 a 44 e 65 a 74 anos, no total de 30 indivíduos para cada faixa etária examinada, com erro amostral de 0,7 e nível de confiança de $90 \%$.

As idades utilizadas na amostra foram selecionadas de acordo com a sugestão de idades-índices sugeridas pela OMS para a realização de levantamentos epidemiológicos (Brasil, 2000), devido aos seguintes aspectos:

12 anos: idade na qual as crianças deixam a escola primária, e por isso, em muitos países, é a última idade na qual pode ser obtida facilmente uma amostra confiável através do sistema escolar. Nesta idade provavelmente todos os dentes permanentes estão erupcionados, com exceção dos terceiros molares.

15-19 anos: aos 15 anos os dentes permanentes foram expostos ao meio bucal por 3 a 9 anos podendo-se comparar o impacto da doença cárie com a idade de 12 anos, é importante também para verificar a doença periodontal em adolescentes. A avaliação da idade de 18 anos é importante 
para obter o perfil das doenças bucais em adultos jovens e é usada com referência de padrões internacionais. Seguindo recomendações do Ministério da Saúde para o levantamento das condições de saúde bucal da população brasileira no ano 2000 a faixa etária foi ampliada para 15 a 19 anos, para maior definição amostral.

35-44 anos: grupo etário padrão para avaliação das condições de saúde bucal nos adultos.

65-74 anos: importante devido ao aumento da expectativa de vida da população. Os dados são necessários tanto para planejamento adequado do tratamento para os mais idosos como para o monitoramento dos efeitos gerais dos serviços odontológicos prestados a uma população.

Para a coleta de dados, foi utilizada ficha com dados de identificação do paciente e os índices adotados na pesquisa foram: Índice do Uso e Necessidade de Prótese Dentária, Índice de Condição Dentária e Necessidade de Tratamento e Índice Periodontal Comunitário de Necessidade de Tratamento, de acordo com orientação da Organização Mundial de Saúde (OMS, 1999) e Manual do Examinador do Projeto SB 2000 - Condições de Saúde Bucal da População Brasileira no Ano 2000 (Brasil, 2001).

Os dados coletados foram tabulados, apresentados sob a forma de gráficos e tabelas elaborados pelo programa Excel da Microsoft e submetidos a tratamento estatístico através de análise descritiva e teste tstudent, com o objetivo de verificar a existência de diferença entre o ICPO-D 
em relação ao sexo em cada faixa etária, utilizando um nível de confiança de $5 \%(p<0,05)$. 


\section{RESULTADOS}

Os resultados obtidos através do tratamento estatístico da amostra foram analisados e são apresentados nas Tabelas 5.1 a 5.18 e nos Gráficos 5.1 a 5.3 a seguir:

Tabela 5.1 - Distribuição em percentual e números absolutos, segundo faixas etárias e sexo de 120 pacientes examinados no Curso de Odontologia da UFPA, 2002

\begin{tabular}{l|c|c|c|c|c|c}
\hline \multirow{2}{*}{ Sexo } & \multicolumn{2}{|c|}{ Masculino } & \multicolumn{2}{c|}{ Feminino } & \multicolumn{2}{c}{ Total } \\
\cline { 2 - 7 } Idade & $\mathbf{n}$ & $\%$ & $\mathbf{n}$ & $\%$ & $\mathbf{n}$ & $\%$ \\
\hline 12 anos & 21 & 38.2 & 9 & 13.8 & 30 & 25.0 \\
15 a 19 anos & 17 & 30.9 & 13 & 20.0 & 30 & 25.0 \\
35 a 44 anos & 8 & 14.5 & 22 & 33.8 & 30 & 25.0 \\
65 a 74 anos & 9 & 16.4 & 21 & 32.3 & 30 & 25.0 \\
\hline \multicolumn{1}{c|}{ Total } & 55 & 100.0 & 65 & 100.0 & 120 & 100 \\
\hline
\end{tabular}

Os resultados observados na Tabela 5.1 mostram que as mulheres adultas e idosas procuram mais por tratamento odontológico que os homens, situação inversa encontrada entre as crianças e adolescentes. 
Tabela 5.2 - Distribuição em percentual e números absolutos, segundo o gênero e etnia dos 120 pacientes examinados no Curso de Odontologia da UFPA, 2002

\begin{tabular}{l|c|c|c|c|c|c}
\hline \multirow{2}{*}{ Idade } & \multicolumn{2}{|c|}{ Masculino } & \multicolumn{2}{c|}{ Feminino } & \multicolumn{2}{c}{ Total } \\
\cline { 2 - 7 } & $\mathbf{n}$ & $\%$ & $\mathbf{n}$ & $\%$ & $\mathbf{n}$ & $\%$ \\
\hline Branco & 2 & 3.6 & 11 & 16.9 & 13 & 10.8 \\
Negro & 7 & 12.7 & 8 & 12.3 & 15 & 12.5 \\
Pardo & 46 & 83.6 & 46 & 70.8 & 92 & 76.7 \\
\hline \multicolumn{1}{c}{ Total } & 55 & 100.0 & 65 & 100.0 & 120 & 100 \\
\hline
\end{tabular}

Quando observado a etnia dos pacientes que procuram atendimento no Curso de Odontologia da UFPA constata-se que $76,7 \%$ são pardos, $12,5 \%$ negros e $10,8 \%$ brancos.

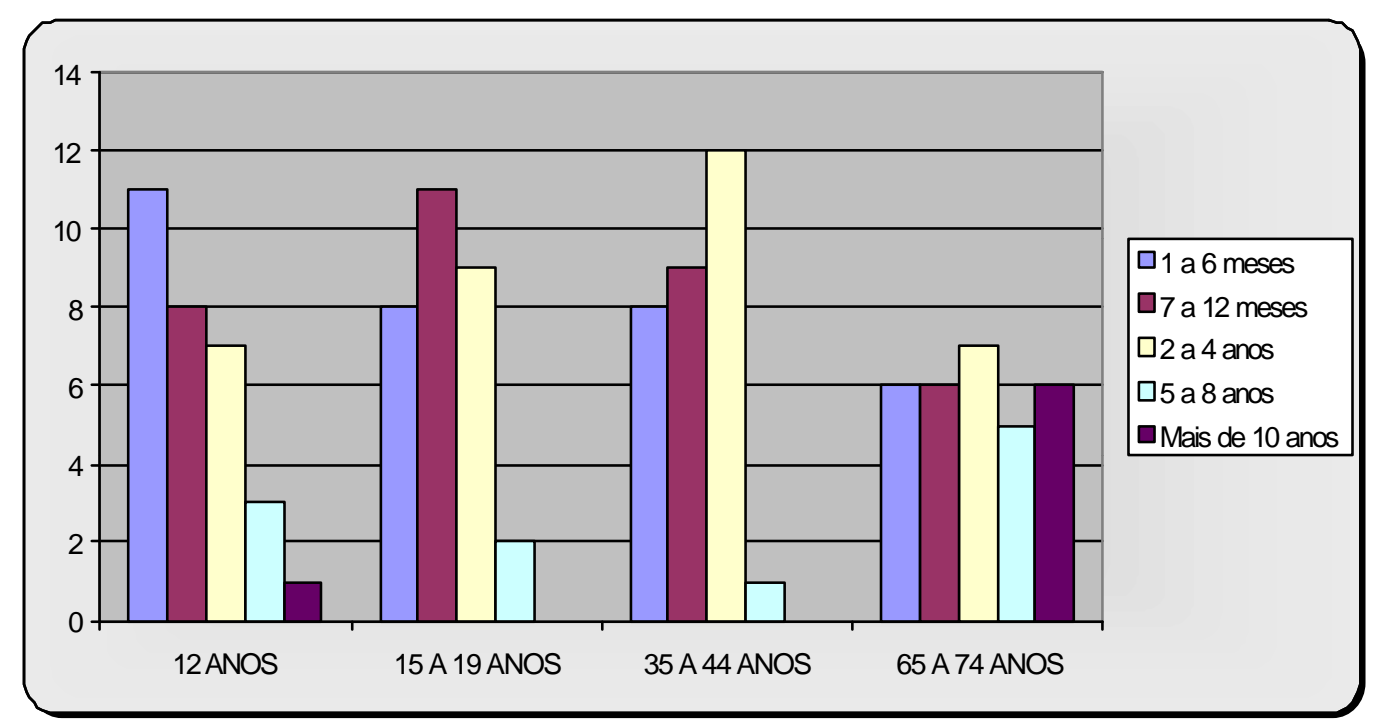

Gráfico 5.1 - Distribuição segundo o tempo decorrido desde o último tratamento odontológico em 120 pacientes examinados no Curso de Odontologia da UFPA, 2002 
Através do Gráfico 5.1 pode-se observar que quanto mais jovem o paciente mais freqüente é a procura pelo tratamento odontológico. Com o aumento da faixa etária o tempo decorrido para a procura de tratamento odontológico vai aumentando.

Tabela 5.3 - ICDNT das coroas dentárias permanentes por faixa etária, em média e percentual, nos 120 pacientes examinados no Curso de Odontologia da UFPA, 2002

\begin{tabular}{|c|c|c|c|c|c|c|c|c|}
\hline \multirow{2}{*}{$\begin{array}{l}\text { Condição } \\
\text { Dentária }\end{array}$} & \multicolumn{2}{|c|}{12 anos } & \multicolumn{2}{|c|}{$15-19$ anos } & \multicolumn{2}{|c|}{35 - 44 anos } & \multicolumn{2}{|c|}{65 - 74 anos } \\
\hline & $\mathbf{x}$ & $\%$ & $x$ & $\%$ & $\mathbf{x}$ & $\%$ & $\mathbf{x}$ & $\%$ \\
\hline Hígidos & $\overline{2}$ & & 231 & 25 & 6 & 7 & 6,6 & 20,6 \\
\hline Caria & & & & & & & & 5,3 \\
\hline $\begin{array}{l}\text { Restaurados } \\
\text { Cariados }\end{array}$ & 0,0 & 0 & 0 & & 0,4 & 1,4 & , , & 0,1 \\
\hline $\begin{array}{l}\text { Restaurados sem } \\
\text { cárie }\end{array}$ & 0,37 & 1 & 0,8 & 2,4 & 2,8 & 8,8 & 0,0 & 0,0 \\
\hline Perdidos por cárie & 0,1 & 0 & 0 & 2,2 & 10,9 & 34,2 & 23,3 & 72,9 \\
\hline $\begin{array}{l}\text { Perdidos por } \\
\text { outras razões }\end{array}$ & 0,0 & 0 , & 0,0 & 0,1 & 0,5 & 1,5 & 0,2 & 0,5 \\
\hline elante & 0,0 & 0 & 0 , & 0,7 & 0 & 0 & 0 , & 0,0 \\
\hline Apoio de pontes & 0,00 & 0,0 & 0,0 & 0,0 & 0,1 & 0,3 & 0,0 & 0,0 \\
\hline & & & & & & & & \\
\hline nados & 5,37 & 17,2 & 3 , & 11,8 & 0 & 1,0 & 0 & 0,2 \\
\hline Tral & 0,10 & 0 , & 0 , & 0,3 & 0 & 0,1 & 0 & 0,1 \\
\hline Dente excluído & 0,00 & 0,0 & 0,0 & 0,0 & 0,0 & 0,0 & 0,1 & 0,2 \\
\hline Total & 31,23 & 100,0 & 31,9 & 100,0 & 32,0 & 100,0 & 32,0 & 100,0 \\
\hline
\end{tabular}

Quando analisada a condição da coroa dentária de dentes permanentes observa-se que 17,12 em média das coroas apresentam-se hígidas, com maior concentração nas faixas etárias de 12 anos e 15-19 anos (24,1 e 23,1 respectivamente). 8,76 coroas em média foram perdidas por cárie, concentrando-se na faixa etária de 35-44 anos (10,9) e 65-74 anos $(23,3)$ o mais alto índice de perdas. 
Tabela 5.4 -ICDNT das coroas dentárias temporárias por faixa etária, em 120 pacientes examinados no Curso de Odontologia da UFPA, 2002

\begin{tabular}{l|c|c|c|c|c}
\hline & 12 anos & $\begin{array}{c}15 \text { a 19 } \\
\text { anos }\end{array}$ & $\begin{array}{c}\text { 35 a 44 } \\
\text { anos }\end{array}$ & $\begin{array}{c}65 \text { a 74 } \\
\text { anos }\end{array}$ & Total \\
\hline Hígidos & 13 & 2 & 1 & 0 & 16 \\
$\begin{array}{l}\text { Cariados } \\
\text { Restaurados sem } \\
\text { cárie }\end{array}$ & 6 & 0 & 0 & 0 & 6 \\
\hline Total & 23 & 3 & 0 & 0 & 5 \\
\hline
\end{tabular}

Em relação as condições das coroas dentárias temporárias, expressas na Tabela 5.4, observa-se que das 27 coroas temporárias existentes, 16 encontram-se hígidas, 6 cariadas e 5 restauradas sem cárie.

Tabela 5.5 - ICDNT das raízes dentárias por faixa etária, em 120 pacientes examinados no Curso de Odontologia da UFPA, 2002

\begin{tabular}{l|c|c|c|c|c}
\hline Condição Dentária & $\mathbf{1 2}$ anos & $\begin{array}{c}\mathbf{1 5} \text { a 19 } \\
\text { anos }\end{array}$ & $\begin{array}{c}\mathbf{3 5} \text { a 44 } \\
\text { anos }\end{array}$ & $\begin{array}{c}\mathbf{6 5} \text { a 74 } \\
\text { anos }\end{array}$ & Total \\
\hline Hígidas & 0 & 0 & 6,8 & 6,3 & 13,0 \\
Cariadas & 0 & 0 & 0,0 & 0,2 & 0,2 \\
$\begin{array}{l}\text { Restauradas } \\
\text { Cariadas }\end{array}$ & 0 & 0 & 0,2 & 0,2 & 0,3 \\
$\begin{array}{l}\text { Raiz não exposta } \\
\text { Raiz excluída }\end{array}$ & 0 & 0 & 11,5 & 1,5 & 13,0 \\
\hline \multicolumn{1}{c|}{ Total } & 32,0 & 32,0 & 13,1 & 23,0 & 100,1 \\
\hline
\end{tabular}

Observando-se a Tabela 5.5 constata-se que a maioria das raízes estão excluídas, seja na faixa etária de 12 e 15 a 19 anos, onde estas raízes não são examinadas de acordo com as regras do ICDNT, ou porque foram extraídas, como observa-se nas faixas etárias de 35-44 anos (13,1 em média) e 65-74 anos (23,0 em média). 
Tabela 5.6 - Índice Cariados, Perdidos e Obturados (CPO-D) por sexo e faixas etárias, em 120 pacientes examinados no Curso de Odontologia da UFPA, 2000

\begin{tabular}{l|c|c|c|c}
\hline \multicolumn{1}{c|}{ Idade } & Masculino & Feminino & Total & Valor de $\mathbf{P}$ \\
\hline 12 anos & 1,71 & 1,44 & 1,63 & 0,65 \\
15 a 19 anos & 5,65 & 3,31 & 4,63 & 0,13 \\
35 a 44 anos & 17,62 & 16,00 & 16,40 & 0,46 \\
65 a 74 anos & 24,10 & 25,48 & 25,01 & 0,64 \\
\hline
\end{tabular}

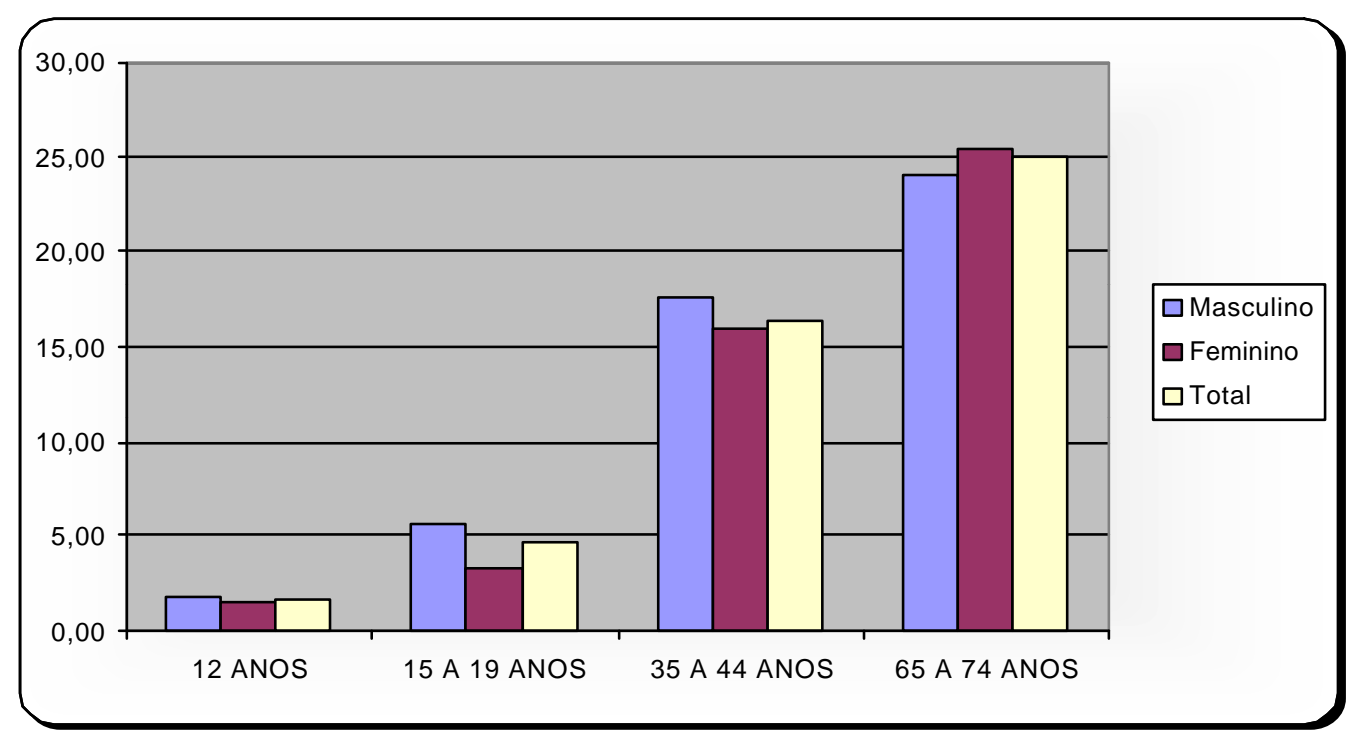

Gráfico 5.2 - Índice Cariados, Perdidos e Obturados (ICPO-D) por sexo e faixas etárias, em 120 pacientes examinados no Curso de Odontologia da UFPA, 2002

Através do ICPO-D expresso na Tabela 5.6 e Gráfico 5.2 pode observar-se que não existe diferença significativa do ICPO-D entre os sexos, quando aplicado o teste t-student, com nível de significância de 5\%. O ICPO-D encontrado na faixa etária de 12 anos $(1,63)$ está dentro dos padrões exigidos pela OMS para o ano 2000, demonstrando uma baixa 
prevalência de cárie dentária. A medida que aumenta a faixa etária, maior é o ICPO-D encontrado, culminado com ICPO-D de 25,01 na faixa etária de 65-74 anos.

Tabela 5.7 - Índice cariados, perdidos e obturados (Iceo-d) para as faixas etárias, em 120 pacientes examinados no Curso de Odontologia da UFPA, 2000

\begin{tabular}{l|c|c|c|c|c}
\hline \multicolumn{1}{c|}{ Iceo-d } & $\mathbf{1 2}$ anos & $\begin{array}{c}15 \text { a } 19 \\
\text { anos }\end{array}$ & $\begin{array}{c}\mathbf{3 5} \text { a } \mathbf{4 4} \\
\text { anos }\end{array}$ & $\begin{array}{c}\mathbf{6 5} \text { a 74 } \\
\text { anos }\end{array}$ & Total \\
\hline Hígidos & 13 & 2 & 1 & 0 & 16 \\
Cariados & 6 & 0 & 0 & 0 & 6 \\
Restaurados & 4 & 1 & 0 & 0 & 5 \\
\hline Total & 0.3 & 0.03 & 0 & 0 & 0.002 \\
\hline
\end{tabular}

O Iceo-d encontrado aos 12 anos, conforme expresso na Tabela 5.7 foi de 0,3 e na faixa de 15-19 anos de 0,03. Na faixa etária de 35 a 44 foi observada a presença de um dente temporário hígido, no maxilar superior, no local do permanente correspondente. 
Tabela 5.8 - Distribuição dos dentes expressos em percentual e média por indivíduo, classificados segundo a necessidade de tratamento, através do ICDNT por faixa etária, em 120 pacientes examinados no Curso de Odontologia da UFPA, 2002

\begin{tabular}{|c|c|c|c|c|c|c|c|c|}
\hline \multirow{2}{*}{$\begin{array}{l}\text { Condição } \\
\text { dentária }\end{array}$} & \multicolumn{2}{|c|}{12 anos } & \multicolumn{2}{|c|}{$15-19$ anos } & \multicolumn{2}{|c|}{35 - 44 anos } & \multicolumn{2}{|c|}{65 - 74 anos } \\
\hline & $\mathbf{x}$ & $\%$ & $\mathbf{x}$ & $\%$ & $\mathbf{x}$ & $\%$ & $\mathbf{x}$ & $\%$ \\
\hline$\overline{\text { Nenh }}$ & 25,1 & 78,5 & 24,8 & 77,6 & $\overline{17,3}$ & 54,0 & 6,6 & 20,6 \\
\hline $\begin{array}{l}\text { Restauração } 1 \\
\text { face }\end{array}$ & 0,9 & 2 & 18 & & 0,9 & & 6 & 2,0 \\
\hline $\begin{array}{l}\text { Restauração } 2 \\
\text { ou + faces }\end{array}$ & 0,1 & 0,3 & 0,6 & 2,0 & 1,4 & 4,4 & 0,7 & 2,2 \\
\hline $\begin{array}{lr}\text { Coroa } & \text { por } \\
\text { qualquer razão }\end{array}$ & 0,0 & 0,0 & 0,0 & 0,0 & 0,0 & 0,1 & 0,2 & 0,7 \\
\hline Faceta estética & 0,0 & 0,0 & 0,0 & 0,0 & 0,0 & 0,0 & 0,0 & 0,0 \\
\hline $\begin{array}{ll}\text { Pulpar } & + \\
\text { restauração }\end{array}$ & 0,2 & 0,6 & 0,3 & 0,8 & 0,0 & 0,1 & 0,1 & 0,3 \\
\hline Extração & 0,1 & 0,4 & 0,1 & 0,2 & 0,2 & 0,7 & 0,2 & 0,5 \\
\hline $\begin{array}{l}\text { Remin. } \\
\text { mancha branca }\end{array}$ & 0,0 & 0,0 & 0,0 & 0,0 & 0,0 & 0,0 & 0,0 & 0,0 \\
\hline Selante & 0,0 & 0,1 & 0,0 & 0,0 & 0,3 & 1,0 & 0,0 & 0,0 \\
\hline $\begin{array}{l}\text { Sem } \\
\text { informação }\end{array}$ & 5,5 & 17,3 & 4,3 & 13,4 & 11,8 & 36,8 & 23,6 & 73,6 \\
\hline Total & 32 & 100,0 & 32 & 100,0 & 32 & 100,0 & 32 & 100,0 \\
\hline
\end{tabular}

Em relação a necessidade de tratamento para a cárie dentária demonstrada na Tabela 5.8, observa-se que a grande maioria dos pacientes não necessita de tratamento, devido os dentes estarem hígidos ou já apresentarem restaurações (18,4 dentes em média) ou por terem dentes extraídos ou não erupcionados (11,3 dentes em média). Necessitam de tratamento restaurador 2,0 dentes em média do total da amostra e de extração 0,15 dentes em média. 
Tabela 5.9 - Distribuição das condições de saúde periodontal por sextante, em percentual e média, segundo o CPITN, em 120 pacientes examinados no Curso de Odontologia da UFPA, 2002

\begin{tabular}{|c|c|c|c|c|c|c|c|c|}
\hline \multirow{2}{*}{$\begin{array}{l}\text { Condições } \\
\text { periodontais }\end{array}$} & \multicolumn{2}{|c|}{12 anos } & \multicolumn{2}{|c|}{ 15-19 anos } & \multicolumn{2}{|c|}{$35-44$ anos } & \multicolumn{2}{|c|}{$65-74$ anos } \\
\hline & 6 & $\%$ & $\mathbf{x}$ & $\%$ & $\mathbf{x}$ & $\%$ & $\mathbf{x}$ & $\%$ \\
\hline Sextante hígido & 1,2 & 20,0 & 1,2 & 19,4 & 0,5 & 7,8 & 0,2 & 2,8 \\
\hline $\begin{array}{l}\text { Sextante } \\
\text { sangramento }\end{array}$ & 2,9 & 47,8 & 2,4 & 40,6 & 1,6 & 26,1 & 0,2 & 2,8 \\
\hline $\begin{array}{l}\text { Sextante } \\
\text { cálculo }\end{array}$ & 1,9 & 31,7 & 1,9 & 31,7 & 2,0 & 33,3 & 0,7 & 11,1 \\
\hline $\begin{array}{l}\text { Bolsa de } 4 \text { a } 5 \\
\mathrm{~mm}\end{array}$ & 0,0 & 0,0 & 0,5 & 8,3 & 0,7 & 11,7 & 0,8 & 12,8 \\
\hline $\begin{array}{l}\text { Bolsa de } 6 \text { ou } \\
\text { mais } \mathrm{mm}\end{array}$ & 0,0 & 0,0 & 0,0 & 0,0 & 0,0 & 0,0 & 0,0 & 0,6 \\
\hline Sextante excluído & 0,0 & 0,5 & 0,0 & 0,0 & 1,3 & 21,1 & 4,2 & 70,0 \\
\hline Total & 6 & 100,0 & 6 & 100,0 & 6 & 100,0 & 6 & 100,0 \\
\hline
\end{tabular}

Os dados referentes as condições de saúde periodontal apresentados na Tabela 5.9, demonstram que aos 12 anos 1,2 sextantes em média estão hígidos, 2,9 apresentam sangramento a sondagem e 1,9 apresentam cálculo. A medida que aumenta a faixa etária a média de sextantes excluídos vai crescendo, assim nas faixas etárias de 12 anos e 15-19 anos não observa-se sextantes excluídos, na faixa etária de 35-44 anos têm-se em média 1,3 sextantes excluídos e dos 65-74 anos 4,2 sextantes estão excluídos. O pior escore encontrado foi de bolsa de 4 a $5 \mathrm{~mm}$ com médias de $0,5,0,7$ e 0,8 nas faixas etárias de 15-19, 35-44 e 65-74 anos respectivamente. 
Tabela 5.10 - Distribuição do número de indivíduos, segundo a pior condição periodontal encontrada, em 120 pacientes examinados no Curso de Odontologia da UFPA, 2002

\begin{tabular}{|c|c|c|c|c|c|}
\hline Sextante & 12 anos & 15 a 19 anos & 35 a 44 anos & 65 a 74 anos & Total \\
\hline Hígido & 1 & 1 & 0 & 0 & 2 \\
\hline Sangramento & 11 & 5 & 0 & 0 & 16 \\
\hline Cálculo & 17 & 13 & 6 & 1 & 37 \\
\hline Bolsa de 4 a $5 \mathrm{~mm}$ & 0 & 11 & 9 & 3 & 23 \\
\hline $\begin{array}{l}\text { Bolsa com } 6 \text { ou } \\
\text { mais mm }\end{array}$ & 0 & 0 & 0 & 1 & 1 \\
\hline Excluído & 1 & 0 & 15 & 25 & 41 \\
\hline Total & 30 & 30 & 30 & 30 & 120 \\
\hline
\end{tabular}

Quando observada a pior situação periodontal encontrada na amostra, pode verificar-se que o maior número de indivíduos está concentrado em sextantes excluídos (41), com predominância das faixas etárias de 35 a 44 anos e 65 a 74 anos, onde já foram extraídos grande quantidade de elementos dentários, seguido de 37 indivíduos com presença de cálculo e 23 com bolsa de 4 a $5 \mathrm{~mm}$. 
Tabela 5.11- Distribuição das necessidades de tratamento periodontal por sextante, em percentual e média, segundo o CPITN em 120 pacientes examinados no Curso de Odontologia da UFPA, 2002

\begin{tabular}{|c|c|c|c|c|c|c|c|c|}
\hline \multirow{2}{*}{$\begin{array}{c}\text { Necessidade } \\
\text { de } \\
\text { tratamento } \\
\end{array}$} & \multicolumn{2}{|c|}{12 anos } & \multicolumn{2}{|c|}{ 15-19 anos } & \multicolumn{2}{|c|}{ 35-44 anos } & \multicolumn{2}{|c|}{ 65-74 anos } \\
\hline & $x$ & $\%$ & $x$ & $\%$ & $x$ & $\%$ & $x$ & $\%$ \\
\hline $\begin{array}{l}\text { Nenhum } \\
\text { Educação em } \\
\text { saúde }\end{array}$ & $\begin{array}{l}1,2 \\
2,9\end{array}$ & $\begin{array}{l}20,0 \\
47,8\end{array}$ & $\begin{array}{l}1,2 \\
2,4\end{array}$ & $\begin{array}{l}19,4 \\
40,6\end{array}$ & $\begin{array}{l}0,5 \\
1,6\end{array}$ & $\begin{array}{c}7,8 \\
26,1\end{array}$ & $\begin{array}{l}0,2 \\
0,2\end{array}$ & $\begin{array}{l}2,8 \\
2,8\end{array}$ \\
\hline $\begin{array}{l}\text { Profilaxia } \\
\text { educação }\end{array}$ & 1,9 & 31,7 & 1,9 & 31,7 & 2,0 & 33,3 & 0,7 & 11,1 \\
\hline $\begin{array}{l}\text { Raspagem }+ \\
\text { profilaxia+ educ. }\end{array}$ & 0,0 & 0,0 & 0,5 & 8,3 & 0,7 & 11,7 & 0,8 & 12,8 \\
\hline $\begin{array}{l}\text { Cirurgia+raspa } \\
\text { gem+profilaxia+ } \\
\text { educação }\end{array}$ & 0,0 & 0,0 & 0,0 & 0,0 & 0,0 & 0,0 & 0,0 & 0,6 \\
\hline Não se aplica & 0,0 & 0,6 & 0,0 & 0,0 & 1,3 & 21,1 & 4,2 & 70,0 \\
\hline Total & 6 & 100,0 & 6 & 100,0 & 6 & 100,0 & 6 & 100,0 \\
\hline
\end{tabular}

Em relação as necessidades de tratamento periodontal dos pacientes que procuram atendimento no Curso de Odontologia da UFPA, expressos na Tabela 5.11, pode-se observar que a maioria dos pacientes necessitam de tratamento sem complexidade como: educação em saúde 2,9 sextantes em média aos 12 anos, 2,4 dos 15-19 anos, 1,6 dos 35-44 anos e 0,2 dos 65-74 anos e profilaxia mais educação com médias por sextantes de 1,9, 1,9, 2,0, 0,7 para as idades de 12 anos, 15-19, 35-44 e 65-74 anos respectivamente. Apenas um paciente precisa de cirurgia periodontal. 
Tabela 5.12 - Distribuição do uso de prótese superior por sexo, nas diversas faixas etárias, em 120 pacientes examinados no Curso de Odontologia da UFPA, 2002

\begin{tabular}{l|c|c|c|c}
\hline \multirow{2}{*}{$\begin{array}{c}\text { Uso } \\
\text { de prótese }\end{array}$} & \multicolumn{2}{|c|}{ Não usa } & \multicolumn{2}{c}{ Usa } \\
\cline { 2 - 5 } 12 anos & Masculino & Feminino & Masculino & Feminino \\
15 a 19 anos & 21 & 9 & 0 & 0 \\
35 a 44 anos & 17 & 13 & 0 & 0 \\
65 a 74 anos & 8 & 14 & 0 & 8 \\
\hline
\end{tabular}

Quando analisado o uso de prótese superior pelos 120 indivíduos participantes da amostra, é possível constatar que a maioria da amostra não usa prótese (100 indivíduos). Dos 20 que utilizam prótese, 85\% são do sexo feminino.

Tabela 5.13 - Distribuição do uso de prótese inferior por sexo, nas diversas faixas etárias, em 120 pacientes examinados no Curso de Odontologia da UFPA, 2002

\begin{tabular}{c|c|c|c|c}
\hline \multirow{2}{*}{$\begin{array}{c}\text { Uso } \\
\text { de prótese }\end{array}$} & \multicolumn{2}{|c|}{ Não usa } & \multicolumn{2}{c}{ Usa } \\
\cline { 2 - 5 } 12 anos & 21 & 9 & 0 & 0 \\
15 a 19 anos & 17 & 13 & 0 & 0 \\
35 a 44 anos & 8 & 20 & 0 & 2 \\
65 a 74 anos & 8 & 19 & 1 & 2 \\
\hline
\end{tabular}

Em relação ao uso de prótese inferior, expressos através da Tabela 5.13, observa-se que apenas 5 pacientes fazem uso de prótese inferior, sendo que $80 \%$ são do sexo feminino. 
Tabela 5.14 - Distribuição em número absoluto e percentual, da necessidade de prótese superior nas diversas faixas etárias, em 120 pacientes examinados no Curso de Odontologia da UFPA, 2002

\begin{tabular}{|c|c|c|c|c|c|c|c|c|}
\hline Necessidade & \multicolumn{2}{|c|}{12 anos } & \multicolumn{2}{|c|}{15 a 19 anos } & \multicolumn{2}{|c|}{35 a 44 anos } & \multicolumn{2}{|c|}{65 a 74 anos } \\
\hline de prótese & $\mathrm{n}$ & $\%$ & $\mathbf{n}$ & $\%$ & $\mathrm{n}$ & $\%$ & $\mathrm{n}$ & $\%$ \\
\hline Não necessita & 30 & 100,0 & 28 & 93,3 & 6 & 20,0 & 2 & 6,7 \\
\hline $\begin{array}{l}\text { Fixa ou Removive } \\
\text { para } 1 \text { elemento } \\
\text { Fixa ou Removíve } \\
\text { para }+ \text { de } 1\end{array}$ & 0 & 0,0 & 0 & 0,0 & 6 & 20,0 & 0 & 0,0 \\
\hline $\begin{array}{l}\text { elemento } \\
\text { Fixa e Removível } \\
\text { para }\end{array}$ & 0 & 0,0 & 0 & 0,0 & 1 & 3,3 & 9 & 30,0 \\
\hline 1 ou + elemento & 0 & 0,0 & 2 & 6,7 & 16 & 53,4 & 4 & 13,3 \\
\hline Prótese Total & 0 & 0,0 & 0 & 0,0 & 1 & 3,3 & 15 & 50,0 \\
\hline Total & 30 & 100,0 & 30 & 100,0 & 30 & 100,0 & 30 & 100,0 \\
\hline
\end{tabular}

Tabela 5.15 - Distribuição em número absoluto e percentual, da necessidade de prótese inferior nas diversas faixas etárias, em 120 pacientes examinados no Curso de Odontologia da UFPA, 2002

\begin{tabular}{|c|c|c|c|c|c|c|c|c|}
\hline \multirow{2}{*}{$\begin{array}{l}\text { Necessidade } \\
\text { de prótese }\end{array}$} & \multicolumn{2}{|c|}{12 anos } & \multicolumn{2}{|c|}{15 a 19 anos } & \multicolumn{2}{|c|}{35 a 44 anos } & \multicolumn{2}{|c|}{65 a 74 anos } \\
\hline & $\mathbf{n}$ & $\%$ & $\mathbf{n}$ & $\%$ & $\mathbf{n}$ & $\%$ & $\mathbf{n}$ & $\%$ \\
\hline Não necessita & 29 & 96,7 & 20 & 66,7 & 4 & 13,3 & 0 & 0,0 \\
\hline $\begin{array}{l}\text { Fixa ou Removíve } \\
\text { para } 1 \text { elemento }\end{array}$ & 1 & 23 & 7 & 2 & 2 & 100 & 0 & 0 \\
\hline $\begin{array}{l}\text { Fixa ou Removíve } \\
\text { para + de } 1\end{array}$ & 1 & 3,3 & 7 & 23,3 & 3 & 10,0 & 0 & 0,0 \\
\hline $\begin{array}{l}\text { elemento } \\
\text { Fixa e Removível } \\
\text { para }\end{array}$ & 0 & 0,0 & 0 & 0,0 & 2 & 6,7 & 13 & 43,4 \\
\hline $1 \mathrm{ou}+$ elemento & 0 & 0,0 & 3 & 10,0 & 21 & 70,0 & 7 & 23,3 \\
\hline Prótese Total & 0 & 0,0 & 0 & 0,0 & 0 & 0,0 & 10 & 33,3 \\
\hline Total & 30 & 100,0 & 30 & 100,0 & 30 & 100,0 & 30 & 100,0 \\
\hline
\end{tabular}

Quando analisados os dados referentes a necessidade de prótese demonstrados na Tabela 5.14 e 5.15, observa-se que 66 pacientes não 
necessitam de prótese superior e 53 de prótese inferior. Em relação a prótese total são necessárias 16 próteses superiores e 10 inferiores, concentrados na faixa de 65 a 74 anos ( $96 \%$ ).

Tabela 5.16 - Distribuição da necessidade de prótese superior por sexo, nas diversas faixas etárias, em 120 pacientes examinados no Curso de Odontologia da UFPA, 2002

\begin{tabular}{l|c|c|c|c}
\hline \multirow{2}{*}{$\begin{array}{c}\text { Necessidade } \\
\text { de prótese }\end{array}$} & \multicolumn{2}{|c|}{ Não necessita } & \multicolumn{2}{c}{ Necessita } \\
\cline { 2 - 5 } & Masculino & Feminino & Masculino & Feminino \\
\hline 12 anos & 21 & 9 & 0 & 0 \\
15 a 19 anos & 15 & 13 & 2 & 0 \\
35 a 44 anos & 0 & 6 & 8 & 16 \\
65 a 74 anos & 0 & 2 & 9 & 19 \\
\hline
\end{tabular}

Tabela 5.17 - Distribuição da necessidade de prótese inferior por sexo, nas diversas faixas etárias, em 120 pacientes examinados no Curso de Odontologia da UFPA, 2002

\begin{tabular}{c|c|c|c|c}
\hline Necessidade & \multicolumn{2}{|c|}{ Não necessita } & \multicolumn{2}{c}{ Necessita } \\
\cline { 2 - 5 } de prótese & Masculino & Feminino & Masculino & Feminino \\
\hline 12 anos & 20 & 9 & 1 & 0 \\
15 a 19 anos & 12 & 8 & 5 & 5 \\
35 a 44 anos & 0 & 4 & 8 & 18 \\
65 a 74 anos & 0 & 0 & 9 & 21 \\
\hline
\end{tabular}

Quando analisadas as necessidades de prótese por sexo, expressas nas Tabelas 5.16 e 5.17, pode perceber-se que todos os pacientes do sexo masculino, nas faixas de 35-44 e 65-74 anos necessitam de algum tipo de prótese superior e inferior, enquanto que no sexo feminino $72,72 \%$ na faixa etária de 35-44 anos e 90,47\% na faixa de 65-74 anos necessitam de 
prótese superior . Em relação a prótese inferior $81,81 \%$ e 100\% necessitam de prótese nas faixas etárias de 35-44 e 65-74 anos respectivamente. Nas faixas etárias de 12 e 15-19 anos nenhum paciente necessita de prótese superior. A necessidade de prótese inferior na faixa etária de 15-19 anos é de $29,41 \%$ para o sexo masculino e $38,46 \%$ para o feminino. Na faixa etária de 12 anos apenas um paciente do sexo masculino necessita de algum tipo de prótese.

Tabela 5.18 - Relação entre o ICPO-D e necessidade de prótese em 120 pacientes examinados no Curso de Odontologia da UFPA

\begin{tabular}{l|c|c|c|c|c|c|c|c}
\hline \multirow{2}{*}{$\begin{array}{l}\text { Necessidade } \\
\text { Idade e ICPO-D }\end{array}$} & \multicolumn{2}{|c|}{12 anos } & \multicolumn{2}{c|}{15 a 19 anos } & \multicolumn{2}{c|}{35 a 44 anos } & \multicolumn{2}{c}{65 a 74 anos } \\
\cline { 2 - 9 } & ICPO-D & $\mathbf{n}$ & ICPO-D & $\mathbf{n}$ & ICPO-D & $\mathbf{n}$ & ICPO-D & $\mathbf{n}$ \\
\hline Não necessita & 1,7 & 29 & 3,8 & 20 & 14,3 & 03 & - & - \\
Necessita & 1,0 & 1 & 6,3 & 10 & 16,7 & 27 & 25,1 & 30 \\
\hline Total & 1,6 & 30 & 4,6 & 30 & 16,4 & 30 & 25,1 & 30 \\
\hline
\end{tabular}




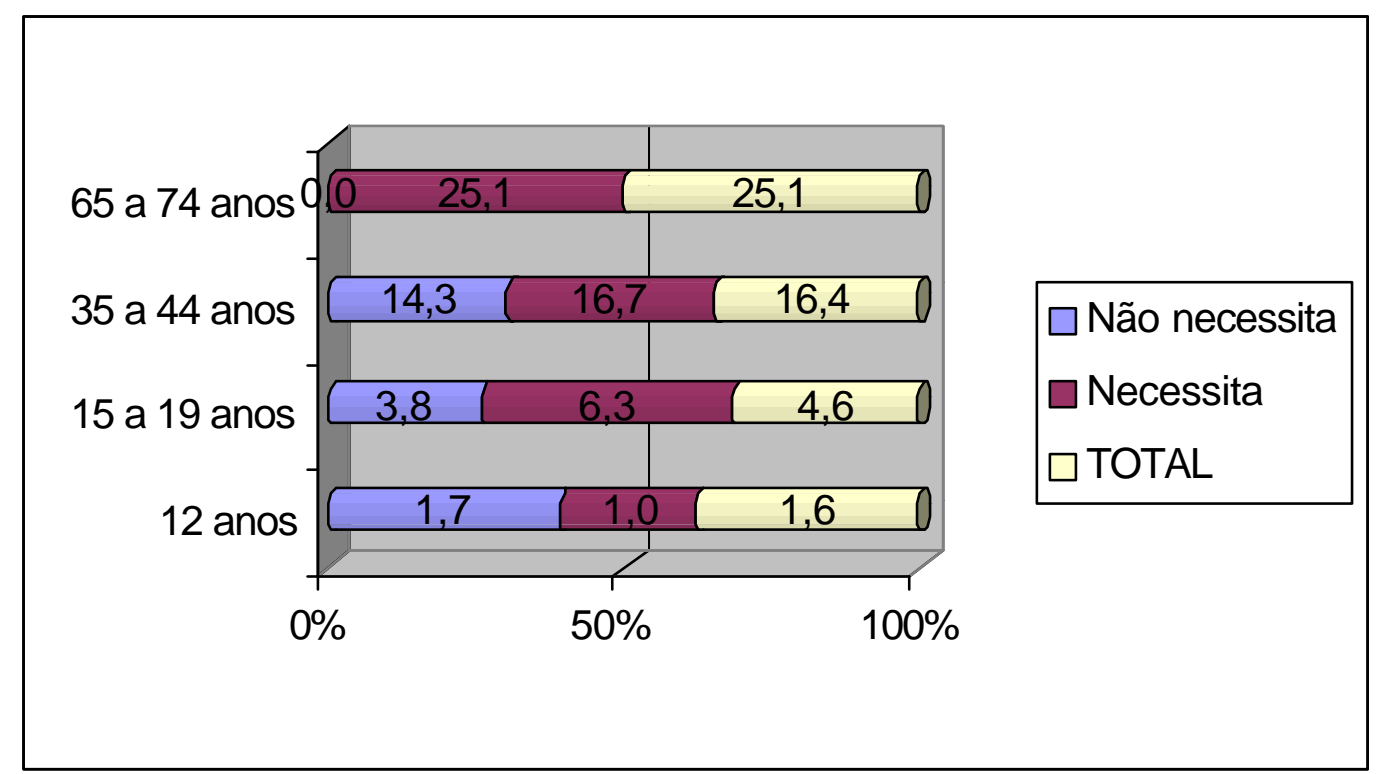

Gráfico 5.3 - Relação entre o ICPO-D e necessidade de prótese em 120 pacientes examinados no Curso de Odontologia da UFPA

Quando se realiza o cruzamento de dados do ICPO-D com a necessidade de prótese dentária nas diversas faixas etárias examinadas, expressas na Tabela 5.18 e Gráfico 5.3, pode-se observar que aos 12 anos onde o ICPO-D dos trinta pacientes examinados é de 1,6, o ICPO-D dos que não necessitam de prótese (29 pacientes) é de 1,7 e dos que necessitam (1 paciente) é de 1,0. Na faixa etária de 15 a 19 anos, 20 pacientes não necessitam de prótese e 10 necessitam, apresentando ICPO-D de 3,8 e 6,3 respectivamente. Quando analisada a faixa etária de 35-44 anos o ICPO-D dos que não necessitam de prótese é de 14,3 e 16,7 dos que necessitam de prótese. Dos 65 aos 74 anos o ICPO-D é de 25,1 para os que necessitam de prótese (30 pacientes), ou seja, toda a amostra examinada nesta faixa etária. 


\section{CONCLUSÕES}

A análise e a discussão dos resultados obtidos no presente trabalho, permitiram concluir que:

1- Os pacientes que procuraram atendimento no Curso de Odontologia da Universidade Federal do Pará, foram em maior prevalência, de cor parda e do sexo feminino .

2- O Índice CPO-D geral da amostra foi de 11,91 e de 1,63 para os 12 anos, 4,63 para a faixa etária de 15 a 19 anos, 16,40 dos 35 aos 44 anos e 25,01 para a faixa etária de 65 a 74 anos.

3- A necessidade de tratamento da cárie dentária predominante foi o tratamento restaurador de uma, duas ou mais faces.

4- Em relação a pior condição periodontal encontrada nos pacientes foi detectada uma alta prevalência da doença periodontal, com alto percentual de sextantes excluídos, seguido da presença de cálculo e bolsa de 4 a $5 \mathrm{~mm}$, levando a uma necessidade de tratamento periodontal concentrada em raspagem, profilaxia e educação de higiene oral. 
5- O uso de prótese ficou concentrado nas faixas etárias de 35 a 44 anos e 65 a 74 anos, onde $26,0 \%$ dos adultos usavam prótese na arcada superior e $6,6 \%$ na inferior enquanto que $40,0 \%$ dos idosos usavam prótese superior e 10,0\% prótese inferior

6- Em relação a necessidade de prótese foi observado que $45 \%$ dos pacientes necessitavam de prótese superior e $54,2 \%$ de prótese inferior. O tipo de prótese mais necessário foi a combinação de próteses fixas e removíveis, seguida de prótese total, que está concentrada na faixa etária de idosos.

7- Quando analisada a necessidade de prótese em relação ao sexo, $41,81 \%$ dos pacientes do sexo masculino e 67,69 do sexo feminino, necessitavam de prótese, demonstrando uma maior necessidade nas mulheres examinadas. 
ANEXOS 


\section{REFERÊNCIAS}

ABOUD, A. B.; PATTUSSI, M. P. Levantamento epidemiológico em saúde bucal - Distrito Federal - 1997. Ação Coletiva, Brasília, v. 1, n. 2, p. 7-16, abr./jun. 1998.

ABRAMOWICZ, M.; GIL, C.; MARTINS, M. C. B. Contribuição para o estudo dos pacientes que freqüentam as clínicas da faculdade de odontologia da USP. Rev Fac Odontol Univ São Paulo, São Paulo, v. 14, n. 2, p. 259270, jul./dez. 1976.

AJWANI, S.; TERVONEN, T.; NÄRHI, T. O.; AINAMO, A. Periodontal health status and treatment needs among the elderly. Spec Care Dentist, Chicago, v. 21, n. 3, p. 98-103, May/June 2001.

ALEKSEJUNIENE, J.; ERIKSEN, H. M.; HOLST, D. Variation in caries and treatment experience in 35-44-year-old Lithuanians. Community Dent Oral Epidemiol, Copenhagen, v. 28, n. 5, p. 356-364, Oct. 2000.

* De acordo com ABNT NBR-6023: 2000. Abreviatura de periódicos segundo Bases de Dados MEDLINE. 
BELAN, L. C. Levantamento das condições de saúde bucal e das necessidades de tratamento em pacientes não submetidos a tratamento prévio na Faculdade de Odontologia da Universidade de São Paulo. 2000. 94 f. Dissertação (Mestrado em Clínica Integrada) Faculdade de Odontologia, Universidade de São Paulo, São Paulo.

BENIGERI, M.; PAYETTE, M; BRODEUR, J. M. Comparison between the DMF indices and two alternative composite indicators of dental health. Community Dent Oral Epidemiol, Copenhagen, v. 26, n. 5, p. 303-309, Oct. 1998.

BRASIL. Ministério da Saúde. Divisão Nacional de Saúde Bucal. Levantamento epidemiológico em saúde bucal: Brasil, zona urbana. 1986. Brasília: Centro de Documentação do Ministério da Saúde, 1988. 137p.

BRASIL. Ministério da Saúde. Secretaria de Assistência àSaúde. Departamento de Assistência e Promoção àSaúde. Coordenação de Saúde Bucal. Levantamento epidemiológico em saúde bucal: $1^{\underline{a}}$ etapa - cárie dental- projeto. Brasília: 1998. 102 p.

BRASIL. Ministério da Saúde. Secretaria de Políticas da Saúde. Departamento de Atenção Básica. Área Técnica de Saúde Bucal. Projeto SB2000: condições de saúde bucal da população brasileira no ano 2000. Brasília: 2000a. 43 p. 
BRASIL. Ministério da Saúde. Secretaria de Políticas da Saúde.

Departamento de Atenção Básica. Área Técnica de Saúde Bucal.

Condições de saúde bucal da população brasileira no ano 2000: estudo piloto em Canela - RS. Brasília: 2000b. 34 p.

BRASIL. Ministério da Saúde. Secretaria de Políticas da Saúde.

Departamento de Atenção Básica. Área Técnica de Saúde Bucal.

Condições de saúde bucal da população brasileira no ano 2000: estudo piloto em Diadema-SP. Brasília: 2000c. 35 p.

BRASIL. Ministério da Saúde. Secretaria de Políticas da Saúde. Departamento de Atenção Básica. Área Técnica de Saúde Bucal. Projeto SB2000: condições de saúde bucal da população brasileira no ano 2000. Manual do examinador. Brasília: 2001. 49 p.

CANGUSSU, M. C. T.; CASTELLANOS, R. A.; PINHEIRO, M. F.; ALBUQUERQUE, S. R.; PINHO, C. Cárie dentária em escolares de 12 e 15 anos de escolas públicas e privadas de Salvador, Bahia, Brasil em 2001. Pesqui Odontol Bras, São Paulo, v. 16, n. 4, p. 379-384, out./dez. 2002. 
CHAISE, R. Levantamento das condições de saúde bucal e necessidades de tratamento de pacientes não submetidos a atendimento prévio que se dirigiram ao setor de triagem da Faculdade de Odontologia da Universidade de Passo Fundo - FOUPF. 2001. 126 f. Dissertação (Mestrado em Clínica Integrada) - Faculdade de Odontologia, Universidade de São Paulo, São Paulo.

CHAVES, M. M. Odontologia social. $3^{\underline{a}}$ ed. São Paulo: Artes Médicas, 1986. $448 \mathrm{p}$.

CORBET, E. F.; WONG, M. C. M.; LIN, H. C. Periodontal conditions in adult Southern Chinese. J Dent Res, Chicago, v. 80, n. 5, p. 1480-1485, May 2001.

EKANAYAKE, L.; WEERASEKARE, C.; EKANAYAKE, N. Needs and demands for dental care in patients attending the University Dental Hospital in Sri Lanka. Int Dent J, Bristol, v. 51, n. 2, p. 67-72, Dec. 2001.

FRAZÃO, P. Epidemiologia em saúde bucal. In: PEREIRA, A. C. (Organizador). Odontologia em saúde coletiva: planejando ações e promovendo saúde. Porto Alegre: Artmed, 2003. cap. 4, p. 64-82.

FREIRE, M. C. M.; PEREIRA, M. F.; BATISTA, S. M. O.; BORGES, M. R. S.; BARBOSA, M. I.; ROSA, A. G. F. Prevalência e necessidade de tratamento em escolares de 6 a 12 anos da rede pública de ensino. Rev Saúde Pública, São Paulo, v. 33, n. 4, p. 385-390, ago. 1999. 
FURTADO, A.; TRAEBERT, J. L.; MARCENES, W. S. Prevalência de doenças bucais e necessidade de tratamento em Capão Alto, Santa Catarina. Rev ABO Nac, São Paulo, v. 7, n. 4, p. 226-230, ago./set. 1999.

GIL, C.; ABRAMOWICZ, M.; SILVA, F.; MELO, L. Situação sócio-econômica de pacientes que freqüentaram as clínicas da faculdade de odontologia da USP: um estudo transversal. RPG, São Paulo, v. 6, n. 1, p. 74-83, jan./mar. 1999.

KOVAC-KAVCIC, M.; SKALERIC, U. The change of DMFT counts in Slovenia. Caries Res, Basel, v. 35, n. 4, p. 247-251, July/Aug. 2001.

LEANDRINI, J. C. D. S. Levantamento das condições de saúde bucal e necessidades de tratamento em pacientes não submetidos a atendimento prévio triados para a disciplina de Clínica Integrada da Faculdade de Odontologia da Universidade de Ribeirão Preto. 2002. 159 f. Dissertação (Mestrado em Clínica Integrada) - Faculdade de Odontologia, Universidade de São Paulo, São Paulo.

LINDEN, M. S. S.; FLÔRES, M. M. D. Z.; TRENTIN, M. S.; CECHETTI, D.; LINDEN, L. A. S.; RECH, C. A.; SILVEIRA, S. Índice das necessidades de tratamento periodontal na comunidade - revisão da literatura. Rev Fac Odontol Passo Fundo, Passo Fundo, v. 7, n. 1, p. 19-22, jan./jun. 2002. 
MacINNIS, W. A.; ISMAIL, A.; MACDONALD, R. M.; FRIARS, C. A. Oral health status and treatment needs of na insured elderly population. J Can Dent Assoc, Ottawa, v. 59, n. 5, p. 465-475, May 1993.

MARCOS, B. Índices de prevalência e de necessidades de tratamento periodontal. Ação Coletiva, Brasília, v. 1, n. 3, p. 29-37, jul./set. 1998.

MARIÑO, R.; WRIGHT, F.; MINAS, I. Oral health among Vietnamese using a community health centre in Richmond, Victoria. Aust Dent J, Sydney, v. 46, n. 3, p. 208-215, Sept. 2001.

MEDEIROS, U. V. Controle clínico da doença cárie. In: GALAN Jr., J.; NAMEN, F. Dentística restauradora "o essencial para o clínico”. São Paulo: Editora Santos, 1998. cap. 2, p. 7-47.

MENEGHIM, M. C.; SALIBA, N. A. Condições de saúde bucal da população idosa de Piracicaba - SP: 1998. RPG, São Paulo, v. 7, n. 1, p. 7-13, jan./mar. 2000.

MENeGHIM, M. C.; PEREIRA, A. C.; SILVA, F. R. B. Prevalência de cárie radicular e condição periodontal em uma população institucionalizada de Piracicaba - SP. Pesqui Odontol Bras, São Paulo, v. 16, n. 1, p. 50-56, jan./mar. 2002. 
MENEZES, A. G. Prevalência da cárie dentária e índice periodontal comunitário de necessidade de tratamento numa população de 15 a 65 anos da cidade de Campo Grande - MS / BRASIL. 1999. $66 \mathrm{f}$. Dissertação (Mestrado em Periodontia) - Faculdade de Odontologia, Universidade de São Paulo, São Paulo.

MICHEELIS, W.; BAUCH, J. Oral health of representative samples of germans examined in 1989 and 1992. Community Dent Oral Epidemiol, Copenhagen, v. 24, n. 1, p. 62-67, Feb. 1996.

MOIMAZ, S. A. S.; TANAKA, H.; GARBIN, C. A. S.; SALIBA, T. A. Prótese dentária - avaliação do uso e necessidade em população adulta. Rev Paul Odontol, São Paulo, ano 24, n. 5, p. 31-34, set./out. 2002.

MOREIRA, B. W.; PEREIRA, A. C.; OLIVEIRA, S. P. Avaliação da prevalência de cárie dentária em escolares de localidade urbana da região Sudeste do Brasil. Rev Saúde Pública, São Paulo,v. 30, n. 3, p. 280-284, 1996.

NARVAI, P. C. Está ocorrendo um declínio da cárie dentária no Brasil? ABOPREV, São Paulo, ano 7, p. 12, mar./abr. 1996.

OLIVEIRA, A. G. R. C. Levantamento epidemiológico em saúde bucal: cárie dental Brasil - 1996 . Araçatuba, 1998. Disponível em: $<$ http.//www.angelonline.cjb.net>. Acesso em: set. 2001. 
OLIVEIRA, A. G. R. C. Perfil epidemiológico de saúde bucal no Brasil 1986-1996 . Disponível em: <http.//www.angelonline.cjb.net>. Acesso em: 27 set. 2002.

OLIVEIRA, A. G. R. C; UNFER, B; COSTA, I. C. C.; ARCEIRI, R. M.; GUIMARÂES, L. O. C; SALIBA, N. A. Análise crítica da metodologia da Organização Mundial de Saúde (OMS) para levantamentos em saúde bucal. 1998. Disponível em: <http.//www.angelonline.cjb.net>. Acesso em: jan. 2003.

ORGANIZAÇÃO MUNDIAL DE SAÚDE. Levantamentos básicos em saúde bucal. 4ª ed. São Paulo: Editora Santos, 1999. 66 p.

PEREIRA, A. C.; MENEGHIM, M. C.; BISCARO, M. R. G.; PINELLI, C.; BASTING, R. T.; SILVA, F. R. B. Índice de necessidades de tratamento em odontologia - um novo conceito em planejamento de serviços. Rev Fac Odontol Lins, Lins, v. 11, n. 2, p. 16-22, jan./jun. 1999.

PINTO, V. G. Saúde bucal coletiva. $4^{\underline{a}}$ ed. São Paulo: Editora Santos, 2000. $541 \mathrm{p}$.

PINTO, V. G. Estudo epidemiológico sobre prevalência de cárie dental em crianças de 3 a 14 anos - Brasil, 1993. Brasília: SESI-DN, 1996. 
PIZANTE, C. R.; GUIMARÃES, L. O. C. Estimativa do erro entre examinadores, usando metodologia da Organização Mundial de Saúde para levantamentos epidemiológicos de saúde bucal. Rev Inst Ciênc Saúde, São Paulo, v. 15, p. 67-72, mar. 1997. Número especial.

REICH, E. Trends in caries and periodontal health epidemiology in Europe. Int Dent J, Bristol, v. 51, n. 6, p. 392-398, Dec. 2001.

RONCALLI, A. G.; FRAZÃO, P.; PATUSSI, M. P.; ARAÚJO, I. C.; ELY, H. C.; BATISTA, S. M. Projeto SB2000: uma perspectiva para a consolidação da epidemiologia em saúde bucal coletiva. Rev Bras Odontol Saúde Coletiva, Brasília, v. 1, n. 2, p. 9-25, jul./dez. 2000.

ROSA, A. G. F.; CASTELLANOS, R. A.; PINTO, V. G. Saúde bucal na terceira idade: um diagnóstico epidemiológico. RGO, Porto Alegre, v. 41, n. 2, p. 97-102, mar./abr. 1993.

SALIBA, C. A.; SALIBA, N. A.; MARCELINO, G.; MOIMAZ, S. A. S. Saúde bucal dos idosos: uma realidade ignorada. Rev Assoc Paul Cir Dent, São Paulo, v. 53, n. 4, p. 279-282, jul./ago. 1999.

SANCHEZ Y., A. E.; TROCONS Z., I.; GERONIMO, M. Necesidades protesicas de los pacientes que asisten a la Facultad de Odontologia de la U.C.V. Acta Odontol Venez, Caracas, v. 36, n. 2, p. 92-99, 1998. 
SÃO PAULO. Secretaria de Estado de Saúde. Faculdade de Saúde Pública da Universidade de São Paulo. Condições de saúde bucal no estado de São Paulo em 2002: relatório final. Disponível em: <www.saude.sp.gov.br>. Acesso em: mar. 2003.

SAUB, R.; EVANS, R. W. Dental needs of elderly hostel residents in inner Melbourne. Aust Dent J, Sydney, v. 46, n. 3, p. 198-202, Sept. 2001.

SCELZA, M. F. Z.; RODRIGUES, C.; SILVA, V. S.; FARIA, L. C. M.; CÂMARA, V.; SCEIZA NETO, P. Saúde bucal dos pacientes do programa interdisciplinar de Geriatria e Gerontologia da UFF. Rev Bras Odontol, Rio de Janeiro, v. 58, n. 5, p. 351- 354, set./out. 2001.

SILVA, B. B.; MALTZ, M. Prevalência de cárie, gengivite e fluorose em escolares de 12 anos de Porto Alegre - RS, Brasil, 1998/1999. Pesqui Odontol Bras, São Paulo, v. 15, n. 3, p. 208-214, jul./set. 2001.

SOARES, M. C.; VIEIRA, V.; FORNI, T. I. B.; JUNQUEIRA, S. R. Condições de saúde bucal no estado de São Paulo, em 2002. Síntese dos principais resultados. APCD J, São Paulo, ano 37, n. 549, p. 14-15, jan. 2003.

SOUSA, M. L. R.; CYPRIANO, S. Sugestões para a etapa de calibração nos levantamentos epidemiológicos em saúde bucal. Odontol Soc, São Paulo, v. 3, n. 1/2, p. 40-46, 2001. 
TRAEBERT, J. L.; PERES, M. A.; GALESSO, E. R.; ZABOT, N. E.;

MARCENES, W. Prevalência e severidade da cárie dentária em escolares de seis e doze anos de idade. Rev Saúde Pública, São Paulo, v. 35, n. 3 , p. 283-288, jun. 2001.

UNIVERSIDADE FEDERAL DO PARÁ. Projeto pedagógico do Curso de Odontologia. Belém: UFPA, 2000. 30 p.

WORLD HEALTH ORGANIZATION. Oral health surveys: basics methods. $4^{\text {th }}$ ed. Geneva: ORH/EPID, 1997. 66 p. 


\section{SUMMARY}

\section{STUDY OF ORAL HEALTH STATUS AND TREATMENT NEEDS \\ IN PATIENTS OF DENTISTRY COURSE OF FEDERAL \\ UNIVERSITY OF PARÁ}

Brazil has often been referred as a country with high indices of prevalence of oral diseases, in particular dental caries and periodontal disease. The main purposes of the present study were to assess the oral health status and treatment needs in dental caries, periodontal disease and prosthetics of patients who looked for treatment in Dentistry Course of Federal University of Pará and to verify the prevalence of these diseases. For this study, 120 patients both male and female were examined and divided into four age groups: $12,15-19 \mathrm{yr}, 35-44 \mathrm{yr}$ and $65-74 \mathrm{yr}$ in 2002 . The parameters were DSTNI, CPITN and wear and need of dental prosthetics, according to WHO. The patients who looked for treatment in Dentistry Course of Federal University of Pará were in higher prevalence, brown and female. The general DMFT index of sample was 11,91 and 1,63 for 12 years old; 4,63 for the age group of $15-19$ years old, 16,40 for $35-44$ years old and 25,01 for the age group of 65-74 years old. The prevailing treatment need of dental caries was restorative treatment of one, two or more faces. The worst periodontal status found in patients was a high prevalence of periodontal diseases with 
high percentage of lost sextants, followed by the presence of calculus and pockets of 4 to $5 \mathrm{~mm}$. There were periodontal treatment needs such as scaling, prophylaxis and oral hygiene instruction. The wear of prosthetics was concentrated in age groups of 35-44 $\mathrm{yr}$ and 65-74 $\mathrm{yr}$. Regard to the prosthetic needs, it was observed that $45 \%$ of patients needed superior prosthetics and $54,2 \%$ inferior prosthetics. When the prosthetic needs were analyzed considering the gender, $41,81 \%$ of male and $67,69 \%$ of female needed to wear prosthetics, showing a higher need in female. 


\section{APÊNDICES}


APÊNDICE 1 - Ficha de levantamento das condições de saúde e necessidades de tratamento dos pacientes

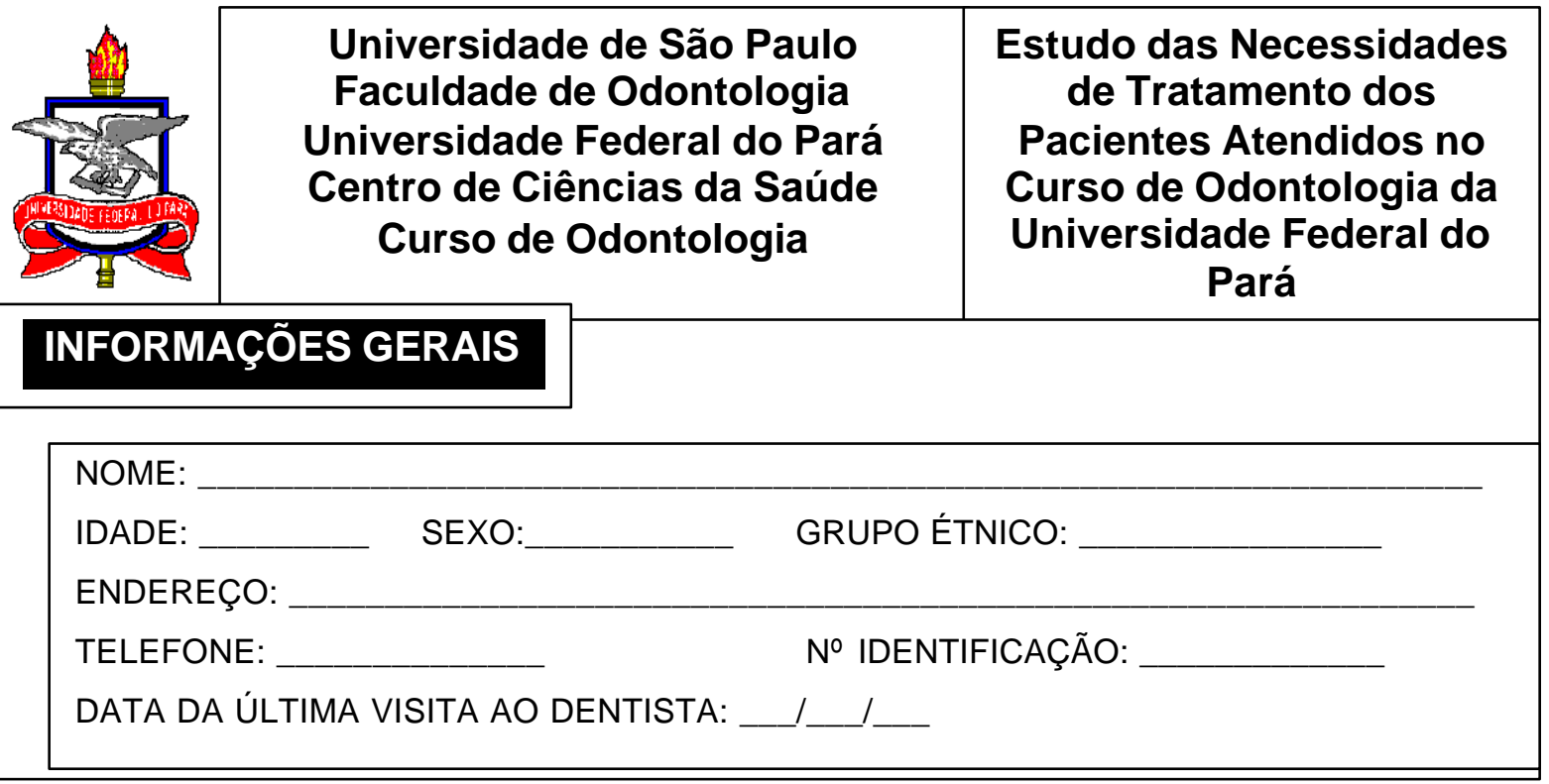

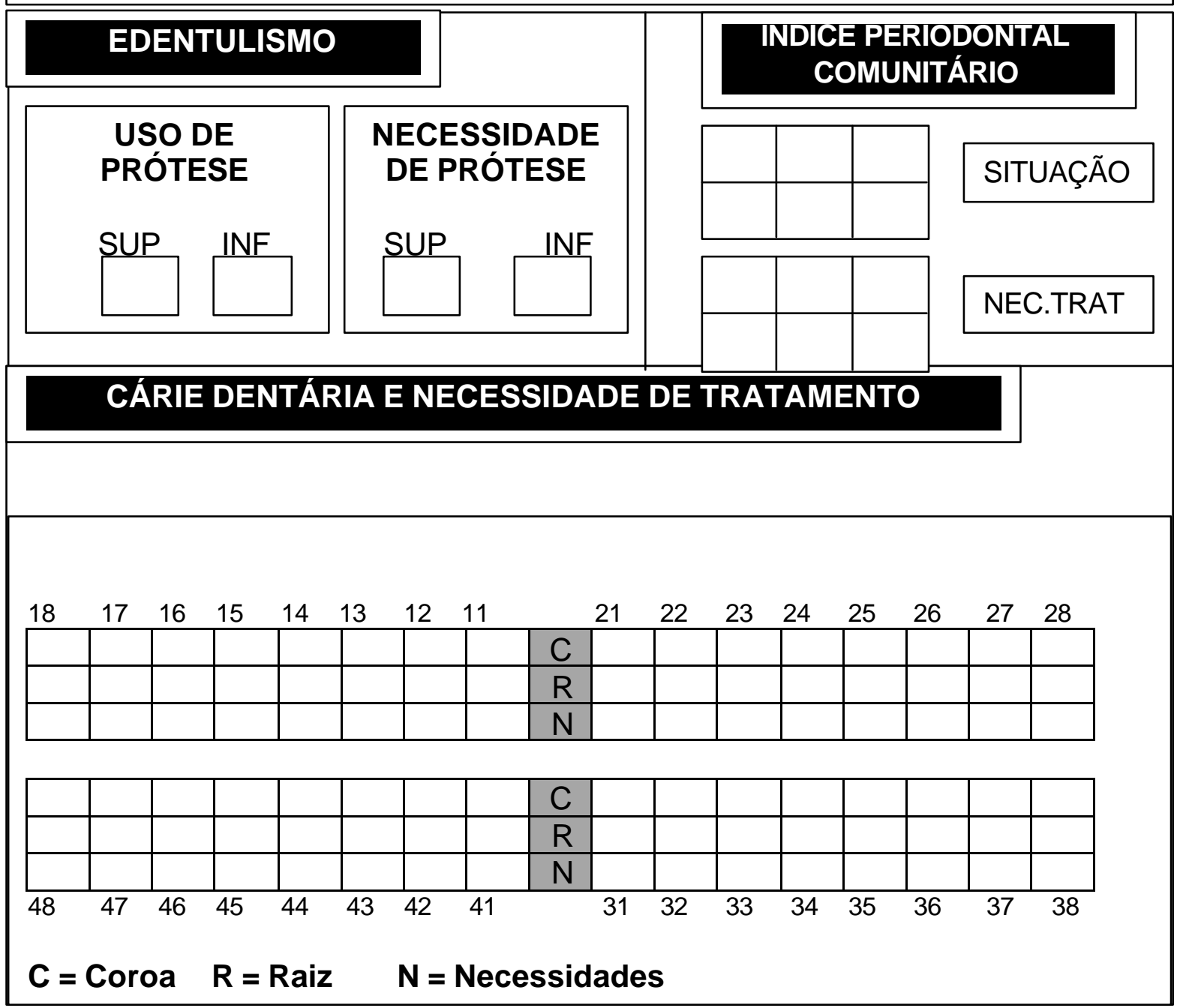


APÊNDICE 2 - Protocolo de Pesquisa

UNIVERSIDADE DE SÃO PAULO

FACULDADE DE ODONTOLOGIA

UNIVERSIDADE FEDERAL DO PARÁ

CENTRO DE CIÊNCIAS DA SAÚDE - CURSO DE ODONTOLOGIA

MESTRADO INTERINSTITUCIONAL DE CLIINICA INTEGRADA

\section{PROTOCOLO DE PESQUISA}

INFORMAČ̃̃ E CONSENTIMENTO PÓS-INFORMAC̄ÃO PARA PESQUISA

NOME DO PACIENTE:

ENDEREÇO:

DOCUMENTO DE IDENTIDADE:

NOME DO PESQUISADOR:

As informações contidas nas fichas clínicas foram levantadas pela Mestranda Marizeli Viana de Aragão Araújo, sob orientação do Profo Dr. Nicolau Tortamano e da Profa. Dra. Regina Fátima Feio Barroso.

Objetivo : Firmar acordo por escrito mediante o qual, o voluntário da pesquisa (paciente ou responsável) autoriza seu exame clínico e divulgação dos dados obtidos, com pleno conhecimento do caráter da pesquisa, tendo capacidade de livre arbítrio e sem qualquer coação, para participar do "Estudo das Condições de Saúde Bucal em Pacientes do Curso de Odontologia da Universidade Federal do Pará" .

* Observação: Para maiores informações estamos a disposição no Curso de Odontologia no telefone (0xx91) 211-1495 e (0xx91) 211-1637.

Belém,

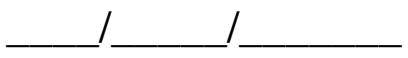

Assinatura do pesquisador

Assinatura do paciente ou responsável 


\title{
AUTORIZAÇÃO
}

Autorizo a reprodução e/ou divulgação total ou parcial da presente obra, por qualquer meio convencional ou eletrônico, desde que citada a fonte e comunicada ao autor, a referência em que consta a citação.

\section{Marizeli Viana de Aragão Araújo}

\author{
Universidade de São Paulo \\ Faculdade de Odontologia \\ Departamento de Estomatologia \\ Disciplina de Clínica Integrada \\ Universidade Federal do Pará \\ Curso de Odontologia \\ Departamento de Clínica Odontológica
}

São Paulo, Junho de 2003.

Av. Prof. Lineu Preste, 2277 - Cidade universitária 05508-900, São Paulo SP - Brasil. Fone: 0055- 11 3818-7816/ 3818-7413

Fax: 0055-11 3032-4409

E-mail: bibfo@ fo.usp.br

Belém - PA. Fone: 91 211-1495 marizeli@nautilus.com.br 